\title{
A COMPARISON OF SIX DIFFERENT ANTIGENS IN THE WASSERMANN REACTION
}

\author{
E. H. RUEDIGER
}

From the Pathological Laboratory of the Bismarck Hospital, Bismarck, N. D.

Because many different kinds of antigens are being used in the Wassermann reaction 6 different kinds of antigen were subjected to comparative study. The antigens studied were alcoholic extract of human heart muscle (A. E. H. H.) ; alcoholic extract of syphilitic fetal liver (A. E. S. F. L.) ; alcoholic extract of dog heart muscle (A. E. D. H.) ; acetone insoluble antigen of dog heart muscle (A. I. D. H.) ; alcoholic extract of sheep heart muscle (A. E. S. H.) and acetone insoluble antigen of sheep heart muscle (A. I. S. H.).

\section{Preparation of Reagents and Technic of Tests}

The antigens used in these tests were prepared in accordance with the usual methods. Fat and fibrous tissue were cut away, blood was washed away, the lean heart muscle was finely minced and $100 \mathrm{gm}$. of minced muscle were extracted with $1,000 \mathrm{cc}$ of absolute alcohol at $37 \mathrm{C}$., with daily shaking, for 2 weeks. The preparation was filtered through paper and, as precipitate was formed, enough alcohol was added to dissolve the precipitate and maintain a clear solution. Acetone insoluble antigen was prepared in accordance with the method of Noguchi as described by Kolmer. ${ }^{2}$ The alcoholic extract of syphilitic fetal liver was purchased from the Wassermann Laboratory, Chicago; beyond that the source is entirely unknown to me.

In Test 1 the largest quantity of turbid antigen solution which was not anticomplementary was compared with a clear solution of the same strength regardless of its anticomplementary property. In all other tests the antigen solutions were turbid and were used in the largest quantities that were not anticomplementary.

All human serums were heated to about $56 \mathrm{C}$. for 30 minutes before they were tested and all except Portion A in Table 4 were glycerolated. Of the glycerol-serum mixture each test tube received $0.2 \mathrm{cc}$. The nonglycerolated portion was mixed with an equal volume of salt solution and of this each test tube received $0.2 \mathrm{cc}$.

As complement the mixed serum of 3 guinea-pigs were used in dilutions of $1: 5,1: 10$ and $1: 20 ; 0.2 \mathrm{c} c$ of diluted complement was used in each test tube.

Antihuman hemolytic amboceptor prepared on a rabbit was used exclusively. With glycerolated human serum the amboceptor was titrated in the presence of $50 \%$ glycerol corresponding to the serum-glycerol mixture used in the test. The smallest quantity which in the presence of $0.2 \mathrm{cc}$ of $1: 10$ dilution of complement completely dissolved the test dose of corpuscles in

Received for publication Aug. 3, 1918.

I Infection, Immunity and Specific Therapy, 1917, p. 446. 
1 hour was called $1 \mathrm{~g}$ unit and was used in the tests. For the nonglycerolated serums glycerol was not used in the titration of amboceptor, the smallest quantity which in the presence of $0.2 \mathrm{c} c$ of $1: 10$ dilution of complement completely dissolved the test dose of corpuscles in 1 hour was called 1 unit and was used in testing the nonglycerolated serums.

The blood corpuscles used were a $2.5 \%$. suspension of washed human blood corpuscles and the test dose was $0.2 \mathrm{c}$.

TABLE 1

Turbid Antigen Solution Compared with Clear Antigen Solution

\begin{tabular}{|c|c|c|c|c|c|c|c|c|c|c|c|}
\hline \multirow{3}{*}{$\begin{array}{c}\text { Number } \\
\text { of } \\
\text { Serum }\end{array}$} & \multirow{3}{*}{$\begin{array}{l}\text { Kind of } \\
\text { Antigen } \\
\text { Solution }\end{array}$} & \multirow{3}{*}{$\begin{array}{c}\text { Antigen } \\
\text { Dilution }\end{array}$} & \multirow{3}{*}{$\begin{array}{c}\text { Ambo- } \\
\text { ceptor } \\
\text { per } \\
\text { Tube } \\
\text { Unit }\end{array}$} & \multicolumn{6}{|c|}{ Readings* } & \multirow{3}{*}{\multicolumn{2}{|c|}{ Results }} \\
\hline & & & & \multicolumn{3}{|c|}{$\begin{array}{c}\text { Antigen } \\
\text { Tubes }\end{array}$} & \multicolumn{3}{|c|}{$\begin{array}{l}\text { Control } \\
\text { Tubes }\end{array}$} & & \\
\hline & & & & 1 & 2 & 3 & $1^{\prime}$ & $2^{\prime}$ & $3^{\prime}$ & & \\
\hline $\begin{array}{l}1 \\
2\end{array}$ & $\begin{array}{l}\text { T'urbid } \\
\text { Clear } \\
\text { Turbid } \\
\text { Clear }\end{array}$ & $\begin{array}{l}1: 30 \\
1: 30 \\
1: 30 \\
1: 30\end{array}$ & $\begin{array}{l}1 \mathbf{g} \\
1 \mathbf{g} \\
1 \mathbf{g} \\
1 \mathbf{g}\end{array}$ & $\begin{array}{l}+ \\
+ \\
+ \\
+\end{array}$ & $\begin{array}{l}+ \\
+ \\
+\end{array}$ & 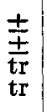 & $\begin{array}{l}+ \\
+ \\
+\end{array}$ & $\begin{array}{l}+ \\
+ \\
+ \\
+\end{array}$ & $\begin{array}{l} \pm \\
\pm \\
\mathbf{t r} \\
\operatorname{tr}\end{array}$ & $\begin{array}{l}\text { Negative, } \\
\text { Negative, } \\
\text { Negative, } \\
\text { Negative, }\end{array}$ & 二. \\
\hline $\begin{array}{l}3 \\
4\end{array}$ & $\begin{array}{l}\text { Turbid } \\
\text { Clear } \\
\text { Turbid } \\
\text { Clear }\end{array}$ & $\begin{array}{l}1: 30 \\
1: 30 \\
1: 30 \\
1: 30\end{array}$ & $\begin{array}{l}1 \mathbf{g} \\
\mathbf{I} \mathbf{g} \\
\mathbf{I} \mathbf{g} \\
\mathbf{1} \mathbf{g}\end{array}$ & $\begin{array}{l}+ \\
+ \\
+ \\
+\end{array}$ & $\begin{array}{l}+ \\
+ \\
+ \\
+\end{array}$ & $\begin{array}{l} \pm \\
\pm \\
\pm \\
\pm\end{array}$ & $\begin{array}{l}+ \\
+ \\
+ \\
+\end{array}$ & $\begin{array}{l}+ \\
+ \\
+ \\
+\end{array}$ & $\begin{array}{l} \pm \\
\pm \\
\pm \\
\pm\end{array}$ & $\begin{array}{l}\text { Negative, } \\
\text { Negative, } \\
\text { Negative, } \\
\text { Negative, }\end{array}$ & $\begin{array}{l}= \\
=\end{array}$ \\
\hline $\begin{array}{l}5 \\
6\end{array}$ & $\begin{array}{l}\text { Turbid } \\
\text { Olear } \\
\text { Turbid } \\
\text { Clear }\end{array}$ & $\begin{array}{l}1: 30 \\
1: 30 \\
1: 30 \\
1: 30\end{array}$ & $\begin{array}{l}1 \mathbf{g} \\
1 \mathbf{g} \\
1 \mathbf{g} \\
1 \mathbf{g}\end{array}$ & $\begin{array}{l}+ \\
+ \\
+ \\
+\end{array}$ & $\begin{array}{l}+ \\
+ \\
+\end{array}$ & $\underset{\mathrm{tr}}{ \pm}$ & $\begin{array}{l}+ \\
+ \\
+ \\
+\end{array}$ & $\begin{array}{l}+ \\
+ \\
+ \\
+\end{array}$ & $\begin{array}{l} \pm \\
t \\
\operatorname{tr} \\
\text { tr }\end{array}$ & $\begin{array}{l}\text { Negative, } \\
\text { Negative, } \\
\text { Negative, } \\
\text { Negative, }\end{array}$ & $\begin{array}{l}= \\
=\end{array}$ \\
\hline $\begin{array}{l}7 \\
8\end{array}$ & $\begin{array}{l}\text { Turbid } \\
\text { Clear } \\
\text { Turbid } \\
\text { Olear }\end{array}$ & $\begin{array}{l}1: 30 \\
1: 30 \\
1: 30 \\
1: 30\end{array}$ & $\begin{array}{l}1 \mathbf{g} \\
1 \mathbf{g} \\
1 \mathbf{g} \\
1 \mathbf{g}\end{array}$ & $\begin{array}{l}+ \\
+ \\
+ \\
+\end{array}$ & $\begin{array}{l}+ \\
+ \\
+ \\
+\end{array}$ & $\begin{array}{l}\operatorname{tr} \\
\operatorname{tr} \\
\pm \\
\pm\end{array}$ & $\begin{array}{l}+ \\
+ \\
+ \\
+\end{array}$ & $\begin{array}{l}+ \\
+ \\
+ \\
+\end{array}$ & $\begin{array}{l}\operatorname{tr} \\
\operatorname{tr} \\
\pm \\
\pm\end{array}$ & $\begin{array}{l}\text { Negative, } \\
\text { Negative, } \\
\text { Negative, } \\
\text { Negative, }\end{array}$ & $\begin{array}{l}= \\
=\end{array}$ \\
\hline $\begin{array}{r}9 \\
10\end{array}$ & $\begin{array}{l}\text { Turbid } \\
\text { Clear } \\
\text { Turbid } \\
\text { Clear }\end{array}$ & $\begin{array}{l}1: 30 \\
1: 30 \\
1: 30 \\
1: 30\end{array}$ & $\begin{array}{l}1 \mathbf{g} \\
1 \mathbf{g} \\
\mathbf{1} \mathbf{g} \\
1 \mathbf{g}\end{array}$ & $\begin{array}{l}+ \\
+ \\
+ \\
+\end{array}$ & $\begin{array}{l}+ \\
+ \\
+ \\
+\end{array}$ & $\begin{array}{l} \pm \\
\pm \\
\pm \\
\pm\end{array}$ & $\begin{array}{l}+ \\
+ \\
+ \\
+\end{array}$ & $\begin{array}{l}+ \\
+ \\
+ \\
+\end{array}$ & $\begin{array}{l} \pm \\
\pm \\
\pm \\
\pm\end{array}$ & $\begin{array}{l}\text { Negative, } \\
\text { Negative, } \\
\text { Negative, } \\
\text { Negative, }\end{array}$ & $=$ \\
\hline $\begin{array}{l}11 \\
12\end{array}$ & $\begin{array}{l}\text { Turbid } \\
\text { Clear } \\
\text { Turbid } \\
\text { Clear }\end{array}$ & $\begin{array}{l}1: 30 \\
1: 30 \\
1: 30 \\
1: 30\end{array}$ & $\begin{array}{l}1 \mathrm{~g} \\
1 \mathbf{g} \\
\mathbf{1} \mathbf{g} \\
1 \mathbf{g}\end{array}$ & $\begin{array}{l}+ \\
+ \\
t r \\
+\end{array}$ & $\begin{array}{c}+ \\
+ \\
+ \\
\text { tr }\end{array}$ & $\begin{array}{l} \pm ? \\
\frac{ \pm}{ \pm} \\
0\end{array}$ & $\begin{array}{l}+ \\
+ \\
+ \\
+\end{array}$ & $\begin{array}{l}+ \\
+ \\
+ \\
+\end{array}$ & $\begin{array}{l} \pm \\
\pm \\
\pm \\
\pm\end{array}$ & $\begin{array}{l}\text { Faintly positive, } \\
\text { Negative, } \\
\text { Strongly positive, } \\
\text { Strongly positive, }\end{array}$ & $\begin{array}{l} \pm \\
8+ \\
4+\end{array}$ \\
\hline $\begin{array}{l}13 \\
14\end{array}$ & $\begin{array}{l}\text { Turbid } \\
\text { Clear } \\
\text { Turbid } \\
\text { Clear }\end{array}$ & $\begin{array}{l}1: 30 \\
1: 30 \\
1: 30 \\
1: 30\end{array}$ & $\begin{array}{l}1 \mathbf{g} \\
\mathbf{1} \mathbf{g} \\
\mathbf{1} \mathbf{g} \\
1 \mathbf{g}\end{array}$ & $\begin{array}{l}+ \\
+ \\
\operatorname{tr} \\
+\end{array}$ & $\begin{array}{l}\text { tr } \\
\pm \\
0 \\
\pm\end{array}$ & $\begin{array}{l}0 \\
0 \\
0 \\
0\end{array}$ & $\begin{array}{l}+ \\
+ \\
+ \\
+\end{array}$ & $\begin{array}{l}+ \\
+ \\
+ \\
+\end{array}$ & $\begin{array}{l}\operatorname{tr} \\
\operatorname{tr} \\
\pm \\
\pm\end{array}$ & $\begin{array}{l}\text { Strongly positive, } \\
\text { Moderately positive, } \\
\text { Strongly positive, } \\
\text { Strongly positive, }\end{array}$ & $\begin{array}{l}3+. \\
2+. \\
8+ \\
3+.\end{array}$ \\
\hline $\begin{array}{l}15 \\
16\end{array}$ & $\begin{array}{l}\text { Turbid } \\
\text { Clear } \\
\text { Turbid } \\
\text { Clear }\end{array}$ & $\begin{array}{l}1: 30 \\
1: 30 \\
1: 30 \\
1: 30\end{array}$ & $\begin{array}{l}1 \mathrm{~g} \\
1 \mathrm{~g} \\
1 \mathbf{g} \\
1 \mathbf{g}\end{array}$ & $\begin{array}{l}\operatorname{tr} \\
+ \\
+ \\
+\end{array}$ & $\begin{array}{l}0 \\
+ \\
\text { tr } \\
+\end{array}$ & $\begin{array}{c}0 \\
\operatorname{tr} \\
0 \\
\operatorname{tr}\end{array}$ & $\begin{array}{l}+ \\
+ \\
+ \\
+\end{array}$ & $\begin{array}{l}+ \\
+ \\
+\end{array}$ & $\frac{ \pm}{ \pm}$ & $\begin{array}{l}\text { Strongly positive, } \\
\text { Weakly positive, } \\
\text { Strongly positive, } \\
\text { Negative, }\end{array}$ & $\begin{array}{l}8+. \\
1+ \\
3+\end{array}$ \\
\hline $\begin{array}{l}17 \\
18\end{array}$ & $\begin{array}{l}\text { Turbid } \\
\text { Clear } \\
\text { Turbid } \\
\text { Clear }\end{array}$ & $\begin{array}{l}1: 30 \\
1: 30 \\
1: 30 \\
1: 30\end{array}$ & $\begin{array}{l}1 \mathbf{g} \\
1 \mathbf{g} \\
1 \mathbf{g} \\
1 \mathbf{g}\end{array}$ & $\begin{array}{l}+ \\
+ \\
+ \\
+\end{array}$ & $\begin{array}{l} \pm \\
+ \\
\text { tr } \\
+\end{array}$ & $\begin{array}{c}0 \\
\pm \\
0 \\
\pm\end{array}$ & $\begin{array}{l}+ \\
+ \\
+ \\
+\end{array}$ & $\begin{array}{l}+ \\
+ \\
+ \\
+\end{array}$ & $\frac{ \pm}{ \pm}$ & $\begin{array}{l}\text { Strongly positive, } \\
\text { Negative, } \\
\text { Strongly positive, } \\
\text { Negative, }\end{array}$ & $\frac{3+}{4}$ \\
\hline $\begin{array}{l}19 \\
20\end{array}$ & $\begin{array}{l}\text { Turbid } \\
\text { Clear } \\
\text { Turbid } \\
\text { Clear }\end{array}$ & $\begin{array}{l}1: 30 \\
1: 30 \\
1: 30 \\
1: 30\end{array}$ & $\begin{array}{l}1 \mathbf{g} \\
1 \mathbf{g} \\
1 \mathbf{g} \\
1 \mathbf{g}\end{array}$ & $\begin{array}{l}+ \\
+ \\
+ \\
+\end{array}$ & $\begin{array}{l} \pm \\
+ \\
+ \\
+\end{array}$ & $\begin{array}{c}0 \\
\pm \\
0 \\
\pm\end{array}$ & $\begin{array}{l}+ \\
+ \\
+ \\
+\end{array}$ & $\begin{array}{l}+ \\
+ \\
+\end{array}$ & $\begin{array}{l} \pm \\
\pm \\
\pm \\
\pm\end{array}$ & $\begin{array}{l}\text { Strongly positive, } \\
\text { Negative, } \\
\text { Moderately positive, } \\
\text { Negative, }\end{array}$ & $\frac{3+.}{2+}$ \\
\hline
\end{tabular}

* In all tables $0=$ no hemolysis; $t r=$ hemolysis up to $50 \% ; \pm=$ hemolysis between $50 \%$ and $100 \% ;+=$ complete hemolysis. 
First incubation was in the refrigerator for 5 hours and second incubation in the incubator at $37 \mathrm{C}$. for 1 hour. The results were read about 3 hours after the corpuscles had been added.

\section{TEST 1}

When alcoholic antigen is slowly diluted with salt solution a turbid or opalescent solution results, while a small quantity of antigen added to a large quantity of salt solution forms a perfectly clear solution. In Test 1 twenty serums, 10 known negatives and 10 known positives, were tested with turbid

TABLE 2

Antigen Adoed After and Before the Comptement

\begin{tabular}{|c|c|c|c|c|c|c|c|c|c|c|c|}
\hline \multirow{3}{*}{$\begin{array}{c}\text { Number } \\
\text { of } \\
\text { Serum }\end{array}$} & \multirow{3}{*}{$\begin{array}{l}\text { Antigen } \\
\text { Added }\end{array}$} & \multirow{3}{*}{$\begin{array}{l}\text { Antigen } \\
\text { Dilution }\end{array}$} & \multirow{3}{*}{$\begin{array}{c}\text { Ambo- } \\
\text { ceptor } \\
\text { per } \\
\text { Tube } \\
\text { Unit } \\
\end{array}$} & \multicolumn{6}{|c|}{ Readings } & \multirow{3}{*}{\multicolumn{2}{|c|}{ Results }} \\
\hline & & & & \multicolumn{3}{|c|}{$\begin{array}{c}\text { Antigen } \\
\text { Tubes }\end{array}$} & \multicolumn{3}{|c|}{$\begin{array}{l}\text { Control } \\
\text { Tubes }\end{array}$} & & \\
\hline & & & & 1 & 2 & 3 & $w_{1}$ & $2^{\prime}$ & $3^{\prime}$ & & \\
\hline $\begin{array}{l}21 \\
22\end{array}$ & $\begin{array}{l}\text { After } \\
\text { Before } \\
\text { After } \\
\text { Before }\end{array}$ & $\begin{array}{l}1: 30 \\
1: 30 \\
1: 30 \\
1: 30\end{array}$ & $\begin{array}{l}1 \mathrm{~g} \\
1 \mathrm{~g} \\
1 \mathrm{~g} \\
1 \mathrm{~g}\end{array}$ & $\begin{array}{l}+ \\
+ \\
+ \\
+ \\
+\end{array}$ & $\begin{array}{l}+ \\
+ \\
+ \\
+\end{array}$ & $\begin{array}{l} \pm \\
\vdots \\
\pm \\
\pm\end{array}$ & $\begin{array}{l}+ \\
+ \\
+1 \\
+ \\
+\end{array}$ & $\begin{array}{l}+ \\
+ \\
+ \\
+\end{array}$ & $\begin{array}{l} \pm \\
\\
\pm \\
\pm\end{array}$ & $\begin{array}{l}\text { Negative, } \\
\text { Negative, } \\
\text { Negative, } \\
\text { Negative, }\end{array}$ & $\begin{array}{l}= \\
=\end{array}$ \\
\hline $\begin{array}{l}23 \\
24\end{array}$ & $\begin{array}{l}\text { After } \\
\text { Before } \\
\text { After } \\
\text { Before }\end{array}$ & $\begin{array}{l}1: 30 \\
1: 30 \\
1: 30 \\
1: 30\end{array}$ & $\begin{array}{l}1 \mathrm{~g} \\
1 \mathrm{~g} \\
\mathrm{l} g \\
\mathrm{ig}\end{array}$ & $\begin{array}{l}+ \\
+ \\
+ \\
+ \\
+\end{array}$ & $\begin{array}{l} \pm \\
\pm \\
+ \\
+\end{array}$ & $\begin{array}{l}\operatorname{tr} \\
\operatorname{tr} \\
\operatorname{tr} \\
\text { tr }\end{array}$ & $\begin{array}{l}+ \\
+ \\
+ \\
+\end{array}$ & $\begin{array}{l}+ \\
+ \\
+ \\
+\end{array}$ & $\begin{array}{l}\operatorname{tr} \\
\operatorname{tr} \\
\operatorname{tr} \\
\operatorname{tr}\end{array}$ & $\begin{array}{l}\text { Negative, } \\
\text { Negative, } \\
\text { Negative, } \\
\text { Negative, }\end{array}$ & $\begin{array}{l}= \\
\text { 二. }\end{array}$ \\
\hline $\begin{array}{l}25 \\
26\end{array}$ & $\begin{array}{l}\text { After } \\
\text { Before } \\
\text { After } \\
\text { Before }\end{array}$ & $\begin{array}{l}1: 30 \\
1: 30 \\
1: 30 \\
1: 30\end{array}$ & $\begin{array}{l}1 \mathrm{~g} \\
\mathrm{l} g \\
\mathrm{l} \mathrm{g} \\
\mathrm{l} g\end{array}$ & $\begin{array}{l}+ \\
+ \\
+ \\
+\end{array}$ & $\begin{array}{l}+1 \\
+ \\
+1 \\
+1\end{array}$ & $\begin{array}{l}\mathrm{tr} \\
\mathrm{tr} \\
\mathrm{tr} \\
\mathrm{tr}\end{array}$ & $\begin{array}{l}+ \\
+ \\
+ \\
+ \\
+\end{array}$ & $\begin{array}{l}+ \\
+ \\
+ \\
+\end{array}$ & $\begin{array}{l}\operatorname{tr} \\
\text { tr } \\
\text { tr } \\
\text { tr }\end{array}$ & $\begin{array}{l}\text { Negative, } \\
\text { Negative, } \\
\text { Negative, } \\
\text { Negative, }\end{array}$ & $\begin{array}{l}\text { 二. } \\
\text { 二. }\end{array}$ \\
\hline $\begin{array}{l}27 \\
28\end{array}$ & $\begin{array}{l}\text { After } \\
\text { Before } \\
\text { After } \\
\text { Before }\end{array}$ & $\begin{array}{l}1: 30 \\
1: 30 \\
1: 30 \\
1: 30\end{array}$ & $\begin{array}{l}1 \mathrm{~g} \\
1 \mathrm{~g} \\
1 \mathrm{~g} \\
1 \mathrm{~g}\end{array}$ & $\begin{array}{l}+ \\
+ \\
+ \\
+\end{array}$ & $\begin{array}{l}+ \\
+ \\
+ \\
+ \\
+\end{array}$ & $\begin{array}{l}\mathrm{tr} \\
\mathrm{tr} \\
\pm \\
\pm\end{array}$ & $\begin{array}{l}+ \\
+ \\
+ \\
+\end{array}$ & $\begin{array}{l}+ \\
\pm \\
+1 \\
+1\end{array}$ & $\begin{array}{l}\operatorname{tr} \\
\operatorname{tr} \\
\pm \\
\pm\end{array}$ & $\begin{array}{l}\text { Negative, } \\
\text { Negative, } \\
\text { Negative, } \\
\text { Negative, }\end{array}$ & 二: \\
\hline $\begin{array}{l}29 \\
30\end{array}$ & $\begin{array}{l}\text { After } \\
\text { Before } \\
\text { After } \\
\text { Before }\end{array}$ & $\begin{array}{l}1: 30 \\
1: 30 \\
1: 30 \\
1: 30\end{array}$ & $\begin{array}{l}1 \mathrm{~g} \\
\mathrm{l} g \\
\mathrm{i} g \\
\mathrm{i} \\
\mathrm{g}\end{array}$ & $\begin{array}{l}+ \\
+ \\
+ \\
+\end{array}$ & $\begin{array}{l}+ \\
+ \\
+ \\
+\end{array}$ & $\begin{array}{l}\text { tr } \\
\text { tr } \\
\pm \\
\pm\end{array}$ & $\begin{array}{l}+ \\
+ \\
+ \\
+\end{array}$ & $\begin{array}{l}+1 \\
+1 \\
+\end{array}$ & $\begin{array}{l}\operatorname{tr} \\
\operatorname{tr} \\
\pm \\
\pm\end{array}$ & $\begin{array}{l}\text { Negative, } \\
\text { Negative, } \\
\text { Negative, } \\
\text { Negative, }\end{array}$ & $\begin{array}{l}\Rightarrow \\
\Rightarrow\end{array}$ \\
\hline $\begin{array}{l}31 \\
32\end{array}$ & $\begin{array}{l}\text { After } \\
\text { Before } \\
\text { After } \\
\text { Before }\end{array}$ & $\begin{array}{l}1: 30 \\
1: 30 \\
1: 30 \\
1: 30\end{array}$ & $\begin{array}{l}1 \mathrm{~g} \\
\mathrm{l} g \\
1 \mathrm{~g} \\
1 \mathrm{~g}\end{array}$ & $\begin{array}{l}+1 \\
+1 \\
+1\end{array}$ & $\begin{array}{l}\operatorname{tr} \\
\mathrm{tr} \\
\pm \\
\pm\end{array}$ & $\begin{array}{l}0 \\
0 \\
0 \\
0\end{array}$ & $\begin{array}{l}+ \\
+ \\
+ \\
+ \\
+\end{array}$ & $\begin{array}{l}+ \\
+ \\
+ \\
+\end{array}$ & $\begin{array}{l}\operatorname{tr} \\
\operatorname{tr} \\
\pm \\
\pm\end{array}$ & $\begin{array}{l}\text { Strongly positive, } \\
\text { Strongly positive, } \\
\text { Strongly positive, } \\
\text { Strongly positive, }\end{array}$ & $\begin{array}{l}3+. \\
3+. \\
3+. \\
3+.\end{array}$ \\
\hline $\begin{array}{l}33 \\
34\end{array}$ & $\begin{array}{l}\text { After } \\
\text { Before } \\
\text { After } \\
\text { Before }\end{array}$ & $\begin{array}{l}1: 30 \\
1: 30 \\
1: 30 \\
1: 30\end{array}$ & $\begin{array}{l}1 \mathrm{~g} \\
\lg g \\
\lg g\end{array}$ & $\begin{array}{l}+ \\
+ \\
+ \\
+\end{array}$ & $\begin{array}{l}0 \\
0 \\
\pm \\
\pm\end{array}$ & $\begin{array}{l}0 \\
0 \\
0 \\
0\end{array}$ & $\begin{array}{l}+ \\
+ \\
+ \\
+ \\
+\end{array}$ & $\begin{array}{l}+ \\
+ \\
+ \\
+\end{array}$ & 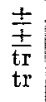 & $\begin{array}{l}\text { Strongly positive, } \\
\text { Strongly positive, } \\
\text { Moderately positive, } \\
\text { Moderately positive, }\end{array}$ & $\begin{array}{l}5+. \\
5+. \\
2+. \\
2+.\end{array}$ \\
\hline $\begin{array}{l}35 \\
36\end{array}$ & $\begin{array}{l}\text { After } \\
\text { Before } \\
\text { After } \\
\text { Before }\end{array}$ & $\begin{array}{l}1: 30 \\
1: 30 \\
1: 30 \\
1: 30\end{array}$ & $\begin{array}{l}1 \mathrm{~g} \\
1 \mathrm{~g} \\
1 \mathrm{~g} \\
1 \mathrm{~g}\end{array}$ & $\begin{array}{l}+ \\
+ \\
+ \\
\operatorname{tr} \\
\operatorname{tr}\end{array}$ & $\begin{array}{l} \pm \\
\pm \\
0\end{array}$ & $\begin{array}{l}0 \\
0 \\
0 \\
0\end{array}$ & $\begin{array}{l}+ \\
+ \\
+ \\
+ \\
+\end{array}$ & $\begin{array}{l}+1 \\
+ \\
+ \\
+\end{array}$ & $\begin{array}{l}\operatorname{tr} \\
\operatorname{tr} \\
\pm \\
\pm\end{array}$ & $\begin{array}{l}\text { Moderately positive, } \\
\text { Moderately positive, } \\
\text { Strongly positive, } \\
\text { Strongly positive, }\end{array}$ & $\begin{array}{l}2+. \\
2+. \\
8+. \\
8+.\end{array}$ \\
\hline $\begin{array}{l}37 \\
38\end{array}$ & $\begin{array}{l}\text { After } \\
\text { Before } \\
\text { After } \\
\text { Before }\end{array}$ & $\begin{array}{l}1: 80 \\
1: 30 \\
1: 30 \\
1: 30\end{array}$ & $\begin{array}{l}1 \mathrm{~g} \\
1 \mathrm{~g} \\
1 \mathrm{~g} \\
1 \mathrm{~g}\end{array}$ & $\begin{array}{l}+ \\
+ \\
+ \\
+\end{array}$ & $\begin{array}{c}0 \\
0 \\
\pm \\
\pm \\
\end{array}$ & $\begin{array}{l}0 \\
0 \\
0 \\
0\end{array}$ & $\begin{array}{l}+ \\
+ \\
+ \\
+\end{array}$ & $\begin{array}{l}+ \\
+ \\
+\end{array}$ & $\frac{ \pm}{ \pm t}$ & $\begin{array}{l}\text { Strongly positive, } \\
\text { Strongly positive, } \\
\text { Moderately positive, } \\
\text { Moderately positive, }\end{array}$ & $\begin{array}{l}5+. \\
5+ \\
2+ \\
2+\end{array}$ \\
\hline $\begin{array}{l}39 \\
40\end{array}$ & $\begin{array}{l}\text { After } \\
\text { Before } \\
\text { After } \\
\text { Before }\end{array}$ & $\begin{array}{l}1: 30 \\
1: 30 \\
1: 30 \\
1: 30\end{array}$ & $\begin{array}{l}1 \mathrm{~g} \\
1 \mathrm{~g} \\
1 \mathrm{~g} \\
1 \mathrm{~g}\end{array}$ & $\frac{ \pm}{ \pm}$ & $\begin{array}{l}0 \\
0 \\
\pm \\
\pm\end{array}$ & $\begin{array}{l}0 \\
0 \\
0 \\
0\end{array}$ & $\begin{array}{l}+ \\
+ \\
+ \\
+\end{array}$ & $\begin{array}{l}+ \\
+ \\
+\end{array}$ & $\begin{array}{l}\text { tr } \\
\text { tr } \\
\pm \\
\pm \\
\end{array}$ & $\begin{array}{l}\text { Strongly positive, } \\
\text { Strongly positive, } \\
\text { Strongly positive, } \\
\text { Strongly positive, }\end{array}$ & $\begin{array}{l}5+. \\
5+. \\
3+. \\
3+.\end{array}$ \\
\hline
\end{tabular}


and with clear antigen solution. The dilutions of the antigen were the same, $1: 30$.

Table 1 shows the results obtained with turbid and with clear antigen solutions on the 10 serums. Serums 1-10, inclusive, gave negative results with both antigen solutions. With Serums 11-20, inclusive, the turbid antigen solution gave much stronger positive results than did the clear antigen solution. Serum 11 gave \pm and a negative result; Serum 12 gave $8+$ and $4+$; Serum 13 gave $3+$ and $2+$; Serum 14 gave $8+$ and $3+$; Serum 15 gave $8+$ and $1+$; Serum 16 gave $3+$ and a negative result; Serum 17 gave $3+$ and a negative result; Serum 18 gave $4+$ and a negative result; Serum 19 gave $3+$ and a negative result; Serum 20 gave $2+$ and a negative result.

TEST 2

In Test 2 twenty serums were tested by adding the antigen after and before the complement. Ordinarily I always mix the ingredients in the following order: (1) human serum; (2) complement, and (3) antigen. First incubation in the refrigerator 5 hours.

Whether antigen was added after or before the complement, the results, as shown in Table 2 were identical throughout.

TEST 3

Test 3 is a comparison of 6 different antigens. The antigens were: alcoholic extract of human heart (A. E. H. H.) ; alcoholic extract of syphilitic fetal liver (A. E. S. F. L.) ; alcoholic extract of dog heart (A. E. D. H.) ; acetone insoluble antigen of dog heart (A. I. D. H.); alcoholic extract of sheep heart (A E. S. H.) ; acetone insoluble antigen of sheep heart (A. I. S. H.). Each antigen was made up in the form of a turbid solution and the largest quantity that was not anticomplementary was used as test dose.

Table 3 shows that the results obtained with the 6 different antigens varied greatly. Serums 41-76, inclusive, came from supposedly nonsyphilitic persons. Serums 77-100, inclusive, came from syphilitics under treatment. Serums 41-61, inclusive, gave negative results with all of the 6 antigens. With Serums 62-76, inclusive, the results varied greatly, the supposed alcoholic extract of syphilitic fetal liver and the antigens prepared from dog heart gave positive results while the human antigen and with a few exceptions the sheep antigens gave negative results. With the known syphilitic serums the alcoholic extract of syphilitic fetal liver usually gave stronger positive results than did the alcoholic extract of human heart. As a rule, the alcoholic extract of dog heart gave stronger positive results than the alcoholic extract of human heart or of syphilitic fetal liver. The acetone 
TABLE 3

Six Drfferent Antigens Compared

\begin{tabular}{|c|c|c|c|c|c|c|c|c|c|c|c|}
\hline \multirow{3}{*}{$\begin{array}{c}\text { Number } \\
\text { of } \\
\text { Serum }\end{array}$} & \multirow{3}{*}{$\begin{array}{c}\text { Kind } \\
\text { of } \\
\text { Antigen }\end{array}$} & \multirow{3}{*}{$\begin{array}{l}\text { Antigen } \\
\text { Dilution }\end{array}$} & \multirow{3}{*}{$\begin{array}{c}\text { Ambo- } \\
\text { ceptor } \\
\text { per } \\
\text { Tube } \\
\text { Unit }\end{array}$} & \multicolumn{6}{|c|}{ Readings } & \multirow{3}{*}{\multicolumn{2}{|c|}{ Results }} \\
\hline & & & & \multicolumn{3}{|c|}{$\begin{array}{c}\text { Antigen } \\
\text { Tubes }\end{array}$} & \multicolumn{3}{|c|}{$\begin{array}{c}\text { Control } \\
\text { Tubes }\end{array}$} & & \\
\hline & & & & 1 & 2 & 3 & $1^{\prime} \mid$ & $2^{\prime}$ & $3^{\prime}$ & & \\
\hline 41 & $\begin{array}{l}\text { A. E. H. H. } \\
\text { A. E. S. F. L. } \\
\text { A. E. D. H. } \\
\text { A. I. D. H. } \\
\text { A. E. S. H. } \\
\text { A. I. S. H. }\end{array}$ & $\begin{array}{l}1: 30 \\
1: 40 \\
1: 30 \\
1: 30 \\
1: 30 \\
1: 30\end{array}$ & $\begin{array}{l}1 \mathrm{~g} \\
1 \mathrm{~g} \\
\mathbf{1} \mathrm{g} \\
1 \mathrm{~g} \\
1 \mathrm{~g} \\
1 \mathrm{~g}\end{array}$ & $\begin{array}{l}+ \\
+ \\
+ \\
+ \\
+ \\
+\end{array}$ & $\begin{array}{l}+ \\
+ \\
+ \\
+ \\
+ \\
+\end{array}$ & $\begin{array}{l} \pm \\
\frac{ \pm}{ \pm} \\
\frac{ \pm}{ \pm} \\
\pm \\
\pm\end{array}$ & $\begin{array}{l}+ \\
+ \\
+ \\
+ \\
+ \\
+ \\
+\end{array}$ & $\begin{array}{l}+ \\
+ \\
+ \\
+ \\
+ \\
+ \\
+\end{array}$ & $\begin{array}{l} \pm \\
\pm \\
\pm \\
\pm \\
\pm \\
\pm\end{array}$ & $\begin{array}{l}\text { Negative, } \\
\text { Negative, } \\
\text { Negative, } \\
\text { Negative, } \\
\text { Negative, } \\
\text { Negative, }\end{array}$ & $\begin{array}{l}= \\
= \\
=\end{array}$ \\
\hline 42 & $\begin{array}{l}\text { A. E. H. H. } \\
\text { A. E. S. F. L. } \\
\text { A. E. D. H. } \\
\text { A. I. D. H. } \\
\text { A. E. S. H. } \\
\text { A. I. S. H. }\end{array}$ & $\begin{array}{l}1: 30 \\
1: 40 \\
1: 30 \\
1: 30 \\
1: 30 \\
1: 30\end{array}$ & $\begin{array}{l}1 \mathrm{~g} \\
1 \mathrm{~g} \\
\mathbf{1} \mathrm{g} \\
1 \mathrm{~g} \\
1 \mathrm{~g} \\
1 \mathrm{~g}\end{array}$ & $\begin{array}{l}+ \\
+ \\
+ \\
+ \\
+ \\
+\end{array}$ & $\begin{array}{l}+ \\
+ \\
+ \\
+ \\
+ \\
+\end{array}$ & $\begin{array}{l}\mathrm{tr} \\
\mathrm{tr} \\
\mathrm{tr} \\
\mathrm{tr} \\
\mathrm{tr} \\
\mathrm{tr}\end{array}$ & $\begin{array}{l}t \\
+ \\
+ \\
+ \\
+\end{array}$ & $\begin{array}{l}+ \\
+ \\
+ \\
+ \\
+ \\
+\end{array}$ & $\begin{array}{l}\operatorname{tr} \\
\operatorname{tr} \\
\operatorname{tr} \\
\mathrm{tr} \\
\mathrm{tr} \\
\mathrm{tr}\end{array}$ & $\begin{array}{l}\text { Negative, } \\
\text { Negative, } \\
\text { Negative, } \\
\text { Negative, } \\
\text { Negative, } \\
\text { Negative, }\end{array}$ & $\begin{array}{l}= \\
= \\
= \\
-\end{array}$ \\
\hline 43 & $\begin{array}{l}\text { A. E. H. H. } \\
\text { A. E. S. F. L. } \\
\text { A. E. D. H. } \\
\text { A. I. D. H. } \\
\text { A. E. S. H. } \\
\text { A.I. S. H. }\end{array}$ & $\begin{array}{l}1: 30 \\
1: 40 \\
1: 30 \\
1: 30 \\
1: 30 \\
1: 30\end{array}$ & $\begin{array}{l}1 \mathrm{~g} \\
1 \mathrm{~g} \\
1 \mathrm{~g} \\
1 \mathrm{~g} \\
1 \mathrm{~g} \\
1 \mathrm{~g}\end{array}$ & $\begin{array}{l}+ \\
+ \\
+ \\
+ \\
+ \\
+ \\
+\end{array}$ & $\begin{array}{l}+ \\
+ \\
+ \\
+ \\
+ \\
+\end{array}$ & $\begin{array}{l}\operatorname{tr} \\
\operatorname{tr} \\
\operatorname{tr} \\
\operatorname{tr} \\
\operatorname{tr} \\
\operatorname{tr}\end{array}$ & $\begin{array}{l}+ \\
+ \\
+ \\
+ \\
+ \\
+\end{array}$ & $\begin{array}{l}+ \\
+ \\
+ \\
+ \\
+ \\
+\end{array}$ & $\mid \begin{array}{l}\mathrm{tr} \\
\mathrm{tr} \\
\mathrm{tr} \\
\mathrm{tr} \\
\mathrm{tr} \\
\mathrm{tr}\end{array}$ & $\begin{array}{l}\text { Negative, } \\
\text { Negative, } \\
\text { Negative, } \\
\text { Negative, } \\
\text { Negative, } \\
\text { Negative, }\end{array}$ & $\begin{array}{l}= \\
= \\
= \\
=\end{array}$ \\
\hline 44 & $\begin{array}{l}\text { A. E. H. H. } \\
\text { A. E.S. F. L. } \\
\text { A. E. D. H. } \\
\text { A. T. D. H. } \\
\text { A. E. S. H. } \\
\text { A. I. S. H. }\end{array}$ & $\begin{array}{l}1: 30 \\
1: 40 \\
1: 30 \\
1: 30 \\
1: 30 \\
1: 30\end{array}$ & $\begin{array}{l}1 \mathbf{g} \\
1 \mathbf{g} \\
\mathbf{1} \mathbf{g} \\
1 \mathbf{g} \\
\mathbf{g} \\
\mathbf{1} \mathbf{g}\end{array}$ & $\begin{array}{l}+ \\
+ \\
+ \\
+ \\
+ \\
+\end{array}$ & $\begin{array}{l}+ \\
+ \\
+ \\
+ \\
+\end{array}$ & $\begin{array}{l} \pm \\
\pm \\
\pm \\
\pm \\
\pm \\
\pm\end{array}$ & $\begin{array}{l}+1 \\
+ \\
+ \\
+ \\
+ \\
+\end{array}$ & $\begin{array}{l}+ \\
+ \\
+ \\
+ \\
+ \\
+\end{array}$ & $\begin{array}{l} \pm \\
\pm \\
\pm \\
\pm \\
\pm\end{array}$ & $\begin{array}{l}\text { Negative, } \\
\text { Negative, } \\
\text { Negative, } \\
\text { Negative, } \\
\text { Negative, } \\
\text { Negative, }\end{array}$ & $\begin{array}{l}= \\
= \\
= \\
=\end{array}$ \\
\hline 45 & $\begin{array}{l}\text { A. E. H. H. } \\
\text { A. E.S. F. L. } \\
\text { A. E. D. H. } \\
\text { A. I. D. } \\
\text { A. E.S.H. } \\
\text { A. I. S. H. }\end{array}$ & $\begin{array}{l}1: 30 \\
1: 40 \\
1: 30 \\
1: 30 \\
1: 30 \\
1: 30\end{array}$ & $\begin{array}{l}1 \mathbf{g} \\
\mathbf{1} \mathbf{g} \\
\mathbf{1} \mathbf{g} \\
\mathbf{1} \mathbf{g} \\
\mathbf{1} \mathbf{g} \\
\mathbf{1} \mathbf{g}\end{array}$ & $\begin{array}{l}+ \\
+ \\
+ \\
+ \\
+ \\
+\end{array}$ & $\begin{array}{l}+ \\
+ \\
+ \\
+ \\
+ \\
+\end{array}$ & $\begin{array}{l} \pm \\
\pm \\
\pm \\
\pm \\
\pm\end{array}$ & $\begin{array}{l}+ \\
+ \\
+ \\
+ \\
+ \\
+ \\
+\end{array}$ & $\begin{array}{l}+ \\
+ \\
+1 \\
+ \\
+ \\
+ \\
+\end{array}$ & $\begin{array}{l}\frac{ \pm}{ \pm} \\
\pm \\
\pm \\
\pm\end{array}$ & $\begin{array}{l}\text { Negative, } \\
\text { Negative, } \\
\text { Negative, } \\
\text { Negative, } \\
\text { Negative, } \\
\text { Negative, }\end{array}$ & $\begin{array}{l}= \\
= \\
= \\
=\end{array}$ \\
\hline 46 & 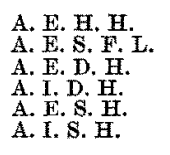 & $\begin{array}{l}1: 30 \\
1: 10 \\
1: 30 \\
1: 30 \\
1: 30 \\
1: 30\end{array}$ & $\begin{array}{l}1 \mathrm{~g} \\
1 \mathrm{~g} \\
1 \mathrm{~g} \\
1 \mathrm{~g} \\
1 \mathrm{~g} \\
1 \mathrm{~g}\end{array}$ & $\begin{array}{l}+ \\
+ \\
+ \\
+ \\
+ \\
+\end{array}$ & $\begin{array}{l}+ \\
+ \\
+ \\
+ \\
+\end{array}$ & $\frac{ \pm}{ \pm}$ & $\begin{array}{l}+ \\
+ \\
+ \\
+ \\
+ \\
+ \\
+\end{array}$ & $\begin{array}{l}+ \\
+ \\
+ \\
+ \\
+ \\
+ \\
+\end{array}$ & $\begin{array}{l} \pm \\
\pm \\
\pm \\
\pm \\
\pm\end{array}$ & $\begin{array}{l}\text { Negative, } \\
\text { Negative, } \\
\text { Negative, } \\
\text { Negative, } \\
\text { Negative, } \\
\text { Negative, }\end{array}$ & $\begin{array}{l}= \\
= \\
= \\
=\end{array}$ \\
\hline 47 & $\begin{array}{l}\text { A. E. H. H. } \\
\text { A. E. S. F. L. } \\
\text { A. E. D. H. } \\
\text { A. I. D. H. } \\
\text { A. E. S. H. } \\
\text { A. I. S. H. }\end{array}$ & $\begin{array}{l}1: 30 \\
1: 40 \\
1: 30 \\
1: 30 \\
1: 30 \\
1: 30\end{array}$ & $\begin{array}{l}1 \mathrm{~g} \\
1 \mathrm{~g} \\
1 \mathrm{~g} \\
1 \mathrm{~g} \\
1 \mathrm{~g} \\
1 \mathrm{~g}\end{array}$ & $\begin{array}{l}+ \\
+ \\
+ \\
+ \\
+ \\
+ \\
+\end{array}$ & $\begin{array}{l}+ \\
+ \\
+ \\
+ \\
+\end{array}$ & 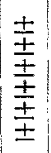 & $\begin{array}{l}+ \\
+ \\
+ \\
+ \\
+ \\
+\end{array}$ & $\begin{array}{l}+ \\
+ \\
+ \\
+ \\
+ \\
+ \\
+\end{array}$ & $\begin{array}{l} \pm \\
\pm \\
\pm \\
\pm \\
\pm\end{array}$ & $\begin{array}{l}\text { Negative, } \\
\text { Negative, } \\
\text { Negative, } \\
\text { Negative, } \\
\text { Negative, } \\
\text { Negative, }\end{array}$ & $\begin{array}{l}= \\
= \\
=\end{array}$ \\
\hline 48 & $\begin{array}{l}\text { A. E. H. H. } \\
\text { A. E. S. F. L. } \\
\text { A. E. D. H. } \\
\text { A. I. D. H. } \\
\text { A. E. S. H. } \\
\text { A. I. S. H. }\end{array}$ & $\begin{array}{l}1: 30 \\
1: 40 \\
1: 30 \\
1: 30 \\
1: 30 \\
1: 30\end{array}$ & $\begin{array}{l}1 \mathbf{g} \\
\mathbf{1} \mathbf{g} \\
\mathbf{l} \mathbf{g} \\
\mathbf{l} \mathbf{g} \\
\mathbf{1} \mathbf{g} \\
\mathbf{l} \mathbf{g}\end{array}$ & $\begin{array}{l}+ \\
+ \\
+ \\
+ \\
+ \\
+ \\
+\end{array}$ & $\begin{array}{l}+ \\
+ \\
+ \\
+ \\
+\end{array}$ & $\frac{ \pm}{\frac{ \pm}{ \pm}}$ & $\begin{array}{l}+ \\
+ \\
+ \\
+ \\
+ \\
+\end{array}$ & $\begin{array}{l}+ \\
+ \\
+ \\
+ \\
+ \\
+ \\
+\end{array}$ & $\begin{array}{l} \pm \\
\pm \\
\pm \\
\pm \\
\pm\end{array}$ & $\begin{array}{l}\text { Negative, } \\
\text { Negative, } \\
\text { Negative, } \\
\text { Negative, } \\
\text { Negative, } \\
\text { Negative, }\end{array}$ & $\begin{array}{l}= \\
= \\
=\end{array}$ \\
\hline 49 & $\begin{array}{l}\text { A. E. H. H. } \\
\text { A. E. S. F. L. } \\
\text { A. D. D. H. } \\
\text { A. I, D. H. } \\
\text { A. E. S. H. } \\
\text { A. I. S. H. }\end{array}$ & $\begin{array}{l}1: 30 \\
1: 40 \\
1: 30 \\
1: 30 \\
1: 30 \\
1: 30\end{array}$ & $\begin{array}{l}1 \mathrm{~g} \\
1 \mathrm{~g} \\
1 \mathrm{~g} \\
1 \mathrm{~g} \\
1 \mathrm{~g} \\
1 \mathrm{~g}\end{array}$ & $\begin{array}{l}+ \\
+ \\
+ \\
+ \\
+ \\
+ \\
+\end{array}$ & $\begin{array}{l}+ \\
+ \\
+ \\
+ \\
+ \\
+\end{array}$ & $\begin{array}{l}\operatorname{tr} \\
\operatorname{tr} \\
\operatorname{tr} \\
\text { tr } \\
\text { tr } \\
\text { tr }\end{array}$ & $\begin{array}{l}+ \\
+ \\
+ \\
+ \\
+ \\
+\end{array}$ & $\begin{array}{l}+ \\
+ \\
+ \\
+ \\
+ \\
+ \\
+\end{array}$ & $\begin{array}{l}\operatorname{tr} \\
\mathrm{tr} \\
\mathrm{tr} \\
\mathrm{tr} \\
\mathrm{tr} \\
\mathrm{tr}\end{array}$ & $\begin{array}{l}\text { Negative, } \\
\text { Negative, } \\
\text { Negative, } \\
\text { Negative, } \\
\text { Negative, } \\
\text { Negative, }\end{array}$ & $\begin{array}{l}\text { 二. } \\
\text { 二. } \\
=\end{array}$ \\
\hline
\end{tabular}


TABLE 3-Continued

Six Different Antigens Compared

\begin{tabular}{|c|c|c|c|c|c|c|c|c|c|c|c|}
\hline \multirow{3}{*}{$\begin{array}{c}\text { Number } \\
\text { of } \\
\text { Serum }\end{array}$} & \multirow{3}{*}{$\begin{array}{c}\text { Kind } \\
\text { of } \\
\text { Antigen }\end{array}$} & \multirow{3}{*}{$\begin{array}{c}\text { Antigen } \\
\text { Dilution }\end{array}$} & \multirow{3}{*}{$\begin{array}{l}\text { Ambo- } \\
\text { ceptor } \\
\text { per } \\
\text { Tube } \\
\text { Unit }\end{array}$} & \multicolumn{6}{|c|}{ Readings } & \multirow{3}{*}{\multicolumn{2}{|c|}{ Results }} \\
\hline & & & & \multicolumn{3}{|c|}{$\begin{array}{l}\text { Antigen } \\
\text { Tubes }\end{array}$} & \multicolumn{3}{|c|}{$\begin{array}{c}\text { Control } \\
\text { Tubes }\end{array}$} & & \\
\hline & & & & 1 & 2 & 3 & $1^{\prime}$ & $2^{\prime}$ & $3^{\prime}$ & & \\
\hline 50 & $\begin{array}{l}\text { A. E. H. H. } \\
\text { A. E. S. F. L. } \\
\text { A. E. D. H. } \\
\text { A. I. D. H. } \\
\text { A. E. S. H. } \\
\text { A. I. S. H. }\end{array}$ & $\begin{array}{l}1: 30 \\
1: 30 \\
1: 30 \\
1: 30 \\
1: 30 \\
1: 30\end{array}$ & $\begin{array}{l}\mathbf{1} \mathbf{g} \\
\mathbf{1} \mathbf{g} \\
\mathbf{1} \mathbf{g} \\
\mathbf{1} \\
\mathbf{g} \\
\mathbf{1} \mathbf{g} \\
\mathbf{1}\end{array}$ & $\begin{array}{l}+ \\
+ \\
+ \\
+ \\
+ \\
+\end{array}$ & $\begin{array}{l}+ \\
+ \\
+ \\
+ \\
+ \\
+\end{array}$ & $\begin{array}{l} \pm \\
\pm \\
\pm \\
\pm \\
\pm\end{array}$ & $\begin{array}{l}+ \\
+ \\
+ \\
+ \\
+\end{array}$ & $\begin{array}{l}+ \\
+ \\
+ \\
+ \\
+\end{array}$ & $\begin{array}{l}\frac{ \pm}{ \pm} \\
\pm \\
\pm \\
\pm \\
\pm\end{array}$ & $\begin{array}{l}\text { Negative, } \\
\text { Negative, } \\
\text { Negative, } \\
\text { Negative, } \\
\text { Negative, } \\
\text { Negative, }\end{array}$ & $\begin{array}{l}= \\
= \\
=\end{array}$ \\
\hline 51 & $\begin{array}{l}\text { A. E. H. H. } \\
\text { A. E. S. F. L. } \\
\text { A. E. D. H. } \\
\text { A. I. D. H. } \\
\text { A. E. S. H. } \\
\text { A. I. S. H. }\end{array}$ & $\begin{array}{l}1: 30 \\
1: 40 \\
1: 30 \\
1: 30 \\
1: 30 \\
1: 30\end{array}$ & $\begin{array}{l}\mathbf{1} \mathbf{g} \\
\mathbf{1} \\
\mathbf{1} \\
\mathbf{g} \\
\mathbf{1} \\
\mathbf{g} \\
\mathbf{1} \\
\mathbf{1} \\
\mathbf{g}\end{array}$ & $\begin{array}{l}+ \\
+ \\
+ \\
+ \\
+ \\
+\end{array}$ & $\begin{array}{l}+ \\
+ \\
+ \\
+ \\
+ \\
+\end{array}$ & $\begin{array}{l} \pm \\
\pm \\
\pm \\
\pm \\
\pm \\
\pm\end{array}$ & $\begin{array}{l}+ \\
+ \\
+ \\
+ \\
+ \\
+\end{array}$ & $\begin{array}{l}+ \\
+ \\
+ \\
+ \\
+ \\
+\end{array}$ & 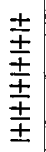 & $\begin{array}{l}\text { Negative, } \\
\text { Negative, } \\
\text { Negative, } \\
\text { Negative, } \\
\text { Negative, } \\
\text { Negative, }\end{array}$ & $\begin{array}{l}= \\
= \\
= \\
=\end{array}$ \\
\hline 52 & $\begin{array}{l}\text { A. E. H. H. } \\
\text { A. E. S. F. L. } \\
\text { A. E. D. H. } \\
\text { A. I. D. H. } \\
\text { A. E. S. H. } \\
\text { A. I. S. H. }\end{array}$ & $\begin{array}{l}1: 30 \\
1: 40 \\
1: 30 \\
1: 30 \\
1: 30 \\
1: 30\end{array}$ & $\begin{array}{l}\mathbf{1} \mathbf{g} \\
\mathbf{I} \\
\mathbf{1} \\
\mathbf{g} \\
\mathbf{1} \\
\mathbf{1} \\
\mathbf{1} \\
\mathbf{g}\end{array}$ & $\begin{array}{l}+ \\
+ \\
+ \\
+ \\
+ \\
+\end{array}$ & $\begin{array}{l}+ \\
+ \\
+ \\
+ \\
+ \\
+ \\
+\end{array}$ & 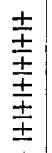 & $\begin{array}{l}+ \\
+ \\
+ \\
+ \\
+ \\
+\end{array}$ & $\begin{array}{l}+ \\
+ \\
+ \\
+ \\
+ \\
+\end{array}$ & $\begin{array}{l} \pm \\
\pm \\
\pm \pm ⿱ 士 \pm \\
\pm \\
\pm\end{array}$ & $\begin{array}{l}\text { Negative, } \\
\text { Negative, } \\
\text { Negative, } \\
\text { Negative, } \\
\text { Negative, } \\
\text { Negative, }\end{array}$ & $\begin{array}{l}= \\
= \\
= \\
=\end{array}$ \\
\hline 53 & $\begin{array}{l}\text { A. E. H. H. } \\
\text { A. E. S. F. L. } \\
\text { A. E. D. H. } \\
\text { A. I. D. H. } \\
\text { A. E. S. H. } \\
\text { A. I. S. H. }\end{array}$ & $\begin{array}{l}1: 30 \\
1: 40 \\
1: 30 \\
1: 30 \\
1: 30 \\
1: 30\end{array}$ & $\begin{array}{l}\mathbf{1} \mathbf{g} \\
\mathbf{1} \mathbf{g} \\
\mathbf{1} \mathbf{g} \\
\mathbf{1} \\
\mathbf{g} \\
\mathbf{1} \\
\mathbf{1} \\
\mathbf{g}\end{array}$ & $\begin{array}{l}+ \\
+ \\
+ \\
+ \\
+ \\
+\end{array}$ & $\begin{array}{l}+ \\
+ \\
+ \\
+ \\
+ \\
+\end{array}$ & $\begin{array}{l} \pm \\
\pm \\
\pm \\
\pm \\
\pm \\
\pm\end{array}$ & $\begin{array}{l}+ \\
+ \\
+ \\
+ \\
+\end{array}$ & $\begin{array}{l}+ \\
+ \\
+ \\
+ \\
+\end{array}$ & 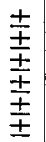 & $\begin{array}{l}\text { Negative, } \\
\text { Negative, } \\
\text { Negative, } \\
\text { Negative, } \\
\text { Negative, } \\
\text { Negative, }\end{array}$ & $\begin{array}{l}= \\
= \\
=\end{array}$ \\
\hline 54 & $\begin{array}{l}\text { A. E. H. H. H. } \\
\text { A. E. S. H. } \\
\text { A. E. D. H. } \\
\text { A. I. D. H. } \\
\text { A. E. S. H. } \\
\text { A. I. S. H. }\end{array}$ & $\begin{array}{l}1: 30 \\
1: 40 \\
1: 30 \\
1: 30 \\
1: 30 \\
1: 30\end{array}$ & $\begin{array}{l}\mathbf{1} \mathbf{g} \\
\mathbf{1} \\
\mathbf{~} \mathbf{g} \\
\mathbf{~} \mathbf{g} \\
\mathbf{~} \mathbf{g} \\
\mathbf{1} \\
\mathbf{g}\end{array}$ & $\begin{array}{l}+ \\
+ \\
+ \\
+ \\
+ \\
+\end{array}$ & $\begin{array}{l}+ \\
+ \\
+ \\
+ \\
+ \\
+\end{array}$ & $\begin{array}{l} \pm \\
\pm \\
\pm \\
\pm \\
\pm \\
\pm\end{array}$ & $\begin{array}{l}+ \\
+ \\
+ \\
+ \\
+ \\
+\end{array}$ & $\begin{array}{l}+ \\
+ \\
+ \\
+ \\
+ \\
+\end{array}$ & $\begin{array}{l}\frac{ \pm}{ \pm} \\
\pm \\
\pm \\
\pm \\
\pm\end{array}$ & $\begin{array}{l}\text { Negative, } \\
\text { Negative, } \\
\text { Negative, } \\
\text { Negative, } \\
\text { Negative, } \\
\text { Negative, }\end{array}$ & $\begin{array}{l}= \\
= \\
=\end{array}$ \\
\hline 55 & $\begin{array}{l}\text { A. E. H. H. H. } \\
\text { A. E. S. H. } \\
\text { A. E. D. H. } \\
\text { A. I. D. H. } \\
\text { A. E. S. H. } \\
\text { A. I. S. H. }\end{array}$ & $\begin{array}{l}1: 30 \\
1: 40 \\
1: 30 \\
1: 30 \\
1: 00 \\
1: 30\end{array}$ & $\begin{array}{l}1 \mathbf{g} \\
\mathbf{g} \\
\mathbf{I} \mathbf{g} \\
\mathbf{1} \mathbf{g} \\
\mathbf{1} \mathbf{g} \\
1 \mathbf{g}\end{array}$ & $\begin{array}{l}+ \\
+ \\
+ \\
+ \\
+ \\
+\end{array}$ & $\begin{array}{l}+ \\
+ \\
+ \\
+ \\
+ \\
+\end{array}$ & $\begin{array}{l}\operatorname{tr} \\
\operatorname{tr} \\
\operatorname{tr} \\
\operatorname{tr} \\
\operatorname{tr} \\
\text { tr }\end{array}$ & $\begin{array}{l}+ \\
+ \\
+ \\
+ \\
+ \\
+\end{array}$ & $\begin{array}{l}+ \\
+ \\
+ \\
+ \\
+\end{array}$ & $\begin{array}{l}\operatorname{tr} \\
\text { tr } \\
\text { tr } \\
\text { tr } \\
\text { tr } \\
\text { tr }\end{array}$ & $\begin{array}{l}\text { Negative, } \\
\text { Negative, } \\
\text { Negative, } \\
\text { Negative, } \\
\text { Negative, } \\
\text { Negative, }\end{array}$ & $\begin{array}{l}= \\
= \\
=\end{array}$ \\
\hline 56 & $\begin{array}{l}\text { A. E. H. H. } \\
\text { A. E. S. F. L. } \\
\text { A. E. D. H. } \\
\text { A. I. D. H. } \\
\text { A. E. S. H. } \\
\text { A. I. S. H. }\end{array}$ & $\begin{array}{l}1: 30 \\
1: 40 \\
1: 30 \\
1: 30 \\
1: 30 \\
1: 30\end{array}$ & $\begin{array}{l}1 \mathbf{g} \\
1 \mathbf{g} \\
1 \mathbf{g} \\
1 \mathbf{g} \\
1 \mathbf{g} \\
1 \mathbf{g}\end{array}$ & $\begin{array}{l}+ \\
+ \\
+ \\
+ \\
+ \\
+\end{array}$ & $\begin{array}{l}+ \\
+ \\
+ \\
+ \\
+ \\
+\end{array}$ & $\begin{array}{l} \pm \\
\pm \\
\pm \\
\pm \\
\pm \\
\pm\end{array}$ & $\begin{array}{l}+ \\
+ \\
+ \\
+ \\
+\end{array}$ & $\begin{array}{l}+ \\
+ \\
+ \\
+ \\
+ \\
+\end{array}$ & 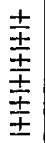 & $\begin{array}{l}\text { Negative, } \\
\text { Negative, } \\
\text { Negative, } \\
\text { Negative, } \\
\text { Negative, } \\
\text { Negative, }\end{array}$ & $\begin{array}{l}= \\
= \\
=\end{array}$ \\
\hline 57 & $\begin{array}{l}\text { A. E. H. H. } \\
\text { A. E. S. F. L. } \\
\text { A. E. D. H. } \\
\text { A. I. D. H. } \\
\text { A. E. S. H. } \\
\text { A. I. S. H. }\end{array}$ & $\begin{array}{l}1: 30 \\
1: 40 \\
1: 30 \\
1: 30 \\
1: 00 \\
1: 30\end{array}$ & $\begin{array}{l}\mathbf{1} \mathbf{g} \\
\mathbf{I} \\
\mathbf{I} \mathbf{g} \\
\mathbf{I} \mathbf{g} \\
\mathbf{I} \\
\mathbf{g} \\
\mathbf{1} \mathbf{g}\end{array}$ & $\begin{array}{l}+ \\
+ \\
+ \\
+ \\
+ \\
+\end{array}$ & $\begin{array}{l}+ \\
+ \\
+ \\
+ \\
+ \\
+\end{array}$ & $\begin{array}{l} \pm \\
\pm \\
\pm \\
\pm \\
\pm \\
\pm\end{array}$ & $\begin{array}{l}+ \\
+ \\
+ \\
+ \\
+ \\
+\end{array}$ & $\begin{array}{l}+ \\
+ \\
+ \\
+ \\
+ \\
+\end{array}$ & $\begin{array}{l} \pm \\
\pm \\
\pm \\
\pm \\
\pm \\
\pm\end{array}$ & $\begin{array}{l}\text { Negative, } \\
\text { Negative, } \\
\text { Negative, } \\
\text { Negative, } \\
\text { Negative, } \\
\text { Negative; }\end{array}$ & $\begin{array}{l}= \\
= \\
=\end{array}$ \\
\hline 58 & $\begin{array}{l}\text { A. E. H. H. } \\
\text { A. E. S. F. L. } \\
\text { A. E. D. H. } \\
\text { A. I. D. H. } \\
\text { A. E. S. H. } \\
\text { A. I. S. H. }\end{array}$ & $\begin{array}{l}1: 30 \\
1: 40 \\
1: 30 \\
1: 30 \\
1: 30 \\
1: 30\end{array}$ & $\begin{array}{l}1 \mathbf{g} \\
\mathbf{1} \mathbf{g} \\
1 \mathbf{g} \\
\mathbf{1} \mathbf{g} \\
1 \mathbf{g} \\
1 \mathbf{g}\end{array}$ & $\begin{array}{l}+ \\
+ \\
+ \\
+ \\
+ \\
+\end{array}$ & $\begin{array}{l}+ \\
+ \\
+ \\
+ \\
+ \\
+\end{array}$ & $\begin{array}{l} \pm \\
\pm \\
\pm \\
\pm \\
\pm \\
\pm\end{array}$ & $\begin{array}{l}+ \\
+ \\
+ \\
+ \\
+\end{array}$ & $\begin{array}{l}+ \\
+ \\
+ \\
+ \\
+ \\
+\end{array}$ & $\begin{array}{l} \pm \\
\pm \\
\pm \\
\pm \\
\pm \\
\pm\end{array}$ & $\begin{array}{l}\text { Negative, } \\
\text { Negative, } \\
\text { Negative, } \\
\text { Negative, } \\
\text { Negative, } \\
\text { Negative, }\end{array}$ & $\begin{array}{l}= \\
= \\
= \\
=\end{array}$ \\
\hline
\end{tabular}


TABLE 3-Continued

Six Different Antigens Compared

\begin{tabular}{|c|c|c|c|c|c|c|c|c|c|c|c|}
\hline \multirow{3}{*}{$\begin{array}{c}\text { Number } \\
\text { of } \\
\text { Serum }\end{array}$} & \multirow{3}{*}{$\begin{array}{c}\text { Kind } \\
\text { of } \\
\text { Antigen }\end{array}$} & \multirow{3}{*}{$\begin{array}{l}\text { Antigen } \\
\text { Dilution }\end{array}$} & \multirow{3}{*}{$\begin{array}{l}\text { Ambo- } \\
\text { ceptor } \\
\text { per } \\
\text { Tube } \\
\text { Unit }\end{array}$} & \multicolumn{6}{|c|}{ Reading ${ }^{*}$} & \multirow{3}{*}{\multicolumn{2}{|c|}{ Results }} \\
\hline & & & & \multicolumn{3}{|c|}{$\begin{array}{l}\text { Antigen } \\
\text { Tubes }\end{array}$} & \multicolumn{3}{|c|}{$\begin{array}{l}\text { Control } \\
\text { Tubes }\end{array}$} & & \\
\hline & & & & 1 & 2 & 3 & $1^{\prime}$ & $2^{\prime \prime}$ & $3^{\prime}$ & & \\
\hline 59 & $\begin{array}{l}\text { A. E. H. H. } \\
\text { A. E. S. F. I. } \\
\text { A. E. D. H. } \\
\text { A. I. D. H. } \\
\text { A. E. S. H. } \\
\text { A. I. S. H. }\end{array}$ & $\begin{array}{l}1: 30 \\
1: 40 \\
1: 30 \\
1: 30 \\
1: 30 \\
1: 30\end{array}$ & $\begin{array}{l}1 \mathrm{~g} \\
1 \mathrm{~g} \\
1 \mathrm{~g} \\
1 \mathrm{~g} \\
1 \mathrm{~g} \\
1 \mathrm{~g}\end{array}$ & $\begin{array}{l}+ \\
+ \\
+ \\
+ \\
+ \\
+\end{array}$ & $\begin{array}{l}+ \\
+ \\
+ \\
+ \\
+ \\
+\end{array}$ & $\begin{array}{l} \pm \\
\pm \\
\pm \\
\pm \\
\pm \\
\pm\end{array}$ & $\begin{array}{l}+ \\
+ \\
+ \\
+ \\
+ \\
+\end{array}$ & $\begin{array}{l}+ \\
+ \\
+ \\
+ \\
+ \\
+\end{array}$ & $\begin{array}{l} \pm \\
\pm \\
\pm \\
\frac{ \pm}{ \pm} \\
\pm\end{array}$ & $\begin{array}{l}\text { Negative, } \\
\text { Negative, } \\
\text { Negative, } \\
\text { Negative, } \\
\text { Negative, } \\
\text { Negative, }\end{array}$ & $\begin{array}{l}- \\
= \\
= \\
-\end{array}$ \\
\hline 60 & $\begin{array}{l}\text { A. F. H. H. } \\
\text { A. E. S. E. L. } \\
\text { A. T. D. H. } \\
\text { A. I. D. H. } \\
\text { A. B. S. H. } \\
\text { A. I. S. H. }\end{array}$ & $\begin{array}{l}1: 30 \\
1: 40 \\
1: 30 \\
1: 30 \\
1: 30 \\
1: 30\end{array}$ & $\begin{array}{l}1 \mathrm{~g} \\
1 \mathrm{~g} \\
1 \mathrm{~g} \\
1 \mathrm{~g} \\
1 \mathrm{~g} \\
1 \mathrm{~g}\end{array}$ & $\begin{array}{l}+ \\
+ \\
+ \\
+ \\
+ \\
+\end{array}$ & $\begin{array}{l}+ \\
+ \\
+ \\
+ \\
+ \\
+\end{array}$ & $\begin{array}{l} \pm \\
\pm \\
\pm \\
\pm \\
\pm\end{array}$ & $\begin{array}{l}+ \\
+ \\
+ \\
+ \\
+ \\
+\end{array}$ & $\begin{array}{l}+ \\
+ \\
+ \\
+ \\
+ \\
+\end{array}$ & $\begin{array}{l} \pm \\
\pm \\
\pm \\
\pm \\
\pm \\
\pm\end{array}$ & $\begin{array}{l}\text { Negative, } \\
\text { Negative, } \\
\text { Negative, } \\
\text { Negative, } \\
\text { Negative, } \\
\text { Negative, }\end{array}$ & $\begin{array}{l}\text { 二. } \\
\text { 二. } \\
\text { - }\end{array}$ \\
\hline 61 & $\begin{array}{l}\text { A. E. H. H. } \\
\text { A. E. S. F. I. } \\
\text { A. F. D. H. } \\
\text { A. I. D. H. } \\
\text { A. E. S. H. } \\
\text { A. I. S. H. }\end{array}$ & $\begin{array}{l}1: 80 \\
1: 40 \\
1: 30 \\
1: 80 \\
1: 30 \\
1: 30\end{array}$ & $\begin{array}{l}1 g \\
1 g \\
1 g \\
1 g \\
1 g \\
1 g\end{array}$ & $\begin{array}{l}+ \\
+ \\
+ \\
+ \\
+ \\
+\end{array}$ & $\begin{array}{l}+ \\
+ \\
+ \\
+ \\
+ \\
+\end{array}$ & $\begin{array}{l}\frac{ \pm}{ \pm} \\
\frac{ \pm}{ \pm} \\
\frac{ \pm}{ \pm}\end{array}$ & $\begin{array}{l}+ \\
+ \\
+ \\
+ \\
+ \\
+\end{array}$ & $\begin{array}{l}+ \\
+ \\
+ \\
+ \\
+\end{array}$ & $\begin{array}{l}\frac{ \pm}{ \pm} \\
\frac{ \pm}{ \pm} \\
\frac{ \pm}{ \pm} \\
\pm\end{array}$ & $\begin{array}{l}\text { Negative, } \\
\text { Negative, } \\
\text { Negative, } \\
\text { Negative, } \\
\text { Negative, } \\
\text { Negative, }\end{array}$ & $\begin{array}{l}\text { - } \\
\text {-: } \\
=\text {. }\end{array}$ \\
\hline 62 & $\begin{array}{l}\text { A. E. H. H. } \\
\text { A. E. S. F. L. } \\
\text { A. E. D. H. } \\
\text { A. I. D. H. } \\
\text { A.E. S. H. } \\
\text { A. I. S. H. }\end{array}$ & $\begin{array}{l}1: 30 \\
1: 40 \\
1: 30 \\
1: 30 \\
1: 30 \\
1: 30\end{array}$ & $\begin{array}{l}1 \mathrm{~g} \\
1 \mathrm{~g} \\
1 \mathrm{~g} \\
1 \mathrm{~g} \\
1 \mathrm{~g} \\
1 \mathrm{~g}\end{array}$ & $\begin{array}{l}+ \\
+ \\
+ \\
+ \\
+ \\
+\end{array}$ & $\begin{array}{l}+ \\
+ \\
\operatorname{tr} \\
0 \\
+ \\
+\end{array}$ & $\begin{array}{c}\text { tr } \\
0 \\
0 \\
0 \\
\text { tr } \\
\text { tr }\end{array}$ & $\begin{array}{l}+ \\
+ \\
+ \\
+ \\
+ \\
+\end{array}$ & $\begin{array}{l}+ \\
+ \\
+ \\
+ \\
+ \\
+\end{array}$ & $\begin{array}{l}\operatorname{tr} \\
\operatorname{tr} \\
\operatorname{tr} \\
\operatorname{tr} \\
\operatorname{tr} \\
\operatorname{tr}\end{array}$ & $\begin{array}{l}\text { Negative, } \\
\text { Weakly positive, } \\
\text { Strongly positive, } \\
\text { Strongly positive, } \\
\text { Negative, } \\
\text { Negative, }\end{array}$ & $\begin{array}{l}1+ \\
3+. \\
3+ \\
-\end{array}$ \\
\hline 63 & $\begin{array}{l}\text { A. E. H. H. } \\
\text { A. E. S. T. L. } \\
\text { A. E. D. H. } \\
\text { A. I. D. H. } \\
\text { A. E. S. H. } \\
\text { A. I. S. H. }\end{array}$ & $\begin{array}{l}1: 30 \\
1: 40 \\
1: 80 \\
1: 30 \\
1: 30 \\
1: 30\end{array}$ & $\begin{array}{l}1 . g \\
1 \mathrm{~g} \\
1 \mathrm{~g} \\
1 \mathrm{~g} \\
1 \mathrm{~g} \\
1 \mathrm{~g}\end{array}$ & $\begin{array}{l}+ \\
+ \\
+ \\
+ \\
+ \\
+\end{array}$ & $\begin{array}{l}+ \\
+ \\
+ \\
+ \\
+ \\
+\end{array}$ & $\begin{array}{c}\operatorname{tr} \\
0 \\
0 \\
0 \\
\operatorname{tr} \\
\text { tr }\end{array}$ & $\begin{array}{l}+ \\
+ \\
+ \\
+ \\
+ \\
+ \\
+\end{array}$ & $\begin{array}{l}+ \\
+ \\
+ \\
+ \\
+ \\
+\end{array}$ & $\begin{array}{l}\operatorname{tr} \\
\operatorname{tr} \\
\operatorname{tr} \\
\operatorname{tr} \\
\operatorname{tr} \\
\operatorname{tr}\end{array}$ & $\begin{array}{l}\text { Negative, } \\
\text { Weakly positive, } \\
\text { Weakly positive, } \\
\text { Moderately positive, } \\
\text { Negative, } \\
\text { Negative, }\end{array}$ & $\begin{array}{l}1+. \\
1+. \\
2+ \\
-\end{array}$ \\
\hline 64 & $\begin{array}{l}\text { A. E.H.H. } \\
\text { A. E.S. F. L. } \\
\text { A. E. D.H. } \\
\text { A.I. D. H. } \\
\text { A. E. S. H. } \\
\text { A.I. S. H. }\end{array}$ & $\begin{array}{l}1: 30 \\
1: 40 \\
1: 80 \\
1: 30 \\
1: 30 \\
1: 80\end{array}$ & $\begin{array}{l}1 \mathrm{~g} \\
1 \mathrm{~g} \\
1 \mathrm{~g} \\
1 \mathrm{~g} \\
1 \mathrm{~g} \\
1 \mathrm{~g}\end{array}$ & $\begin{array}{l}+ \\
+ \\
+ \\
+ \\
+ \\
+ \\
+\end{array}$ & $\begin{array}{l}+ \\
\pm \\
\frac{+}{ \pm} \\
\operatorname{tr} \\
+ \\
+\end{array}$ & $\begin{array}{l} \pm \\
0 \\
0 \\
0 \\
\pm \\
\pm\end{array}$ & $\begin{array}{l}+ \\
+ \\
+ \\
+ \\
+ \\
+\end{array}$ & $\begin{array}{l}+ \\
+ \\
+ \\
+ \\
+ \\
+\end{array}$ & $\begin{array}{l} \pm \\
\pm \\
\pm \\
\pm \\
\pm\end{array}$ & $\begin{array}{l}\text { Negative, } \\
\text { Strongly positive, } \\
\text { Strongly positive, } \\
\text { Strongly positive, } \\
\text { Negative, } \\
\text { Negative, }\end{array}$ & $\begin{array}{l}3+ \\
3+ \\
8+ \\
=\end{array}$ \\
\hline 65 & $\begin{array}{l}\text { A. E. H.H. } \\
\text { A. E.S. F. L. } \\
\text { A. E. D.H. } \\
\text { A. I. D. H. } \\
\text { A. E.S.H. } \\
\text { A. I. S. H. }\end{array}$ & $\begin{array}{l}1: 80 \\
1: 40 \\
1: 30 \\
1: 30 \\
1: 30 \\
1: 30\end{array}$ & $\begin{array}{l}1 \mathrm{~g} \\
1 \mathrm{~g} \\
1 \mathrm{~g} \\
1 \mathrm{~g} \\
1 \mathrm{~g} \\
1 \mathrm{~g}\end{array}$ & $\begin{array}{l}+ \\
+ \\
+ \\
+0 \\
+ \\
+\end{array}$ & $\begin{array}{c}+ \\
t \\
0 \\
0 \\
+ \\
+ \\
+\end{array}$ & $\begin{array}{c}\operatorname{tr} \\
0 \\
0 \\
0 \\
\operatorname{tr} \\
0\end{array}$ & $\begin{array}{l}+ \\
+ \\
+ \\
+ \\
+ \\
+\end{array}$ & $\begin{array}{l}+ \\
+ \\
\frac{1}{+} \\
\frac{1}{+} \\
+\end{array}$ & $\begin{array}{l}\operatorname{tr} \\
\operatorname{tr} \\
\operatorname{tr} \\
\operatorname{tr} \\
\operatorname{tr} \\
\operatorname{tr}\end{array}$ & $\begin{array}{l}\text { Negative, } \\
\text { Strongly positive, } \\
\text { Strongly positive, } \\
\text { Strongly positive, } \\
\text { Negative, } \\
\text { Weakly positive, }\end{array}$ & $\begin{array}{l}\overrightarrow{3+} \\
5+ \\
8+ \\
1+\end{array}$ \\
\hline 66 & $\begin{array}{l}\text { A. E. H.H. } \\
\text { A. E. S. H. L. } \\
\text { A. E. D. H. } \\
\text { A. I. D. H. } \\
\text { A. E. S. H. } \\
\text { A. I. S. H. }\end{array}$ & $\begin{array}{l}1: 30 \\
1: 40 \\
1: 30 \\
1: 30 \\
1: 30 \\
1: 30\end{array}$ & $\begin{array}{l}1 \mathrm{~g} \\
1 \mathrm{~g} \\
\mathrm{I} g \\
1 \mathrm{~g} \\
1 \mathrm{~g} \\
1 \mathrm{~g}\end{array}$ & $\begin{array}{c}+ \\
t r \\
0 \\
\operatorname{tr} \\
+ \\
+\end{array}$ & $\begin{array}{l}+ \\
0 \\
0 \\
0 \\
+ \\
+\end{array}$ & $\begin{array}{l}\operatorname{tr} \\
0 \\
0 \\
0 \\
0 \\
0\end{array}$ & $\begin{array}{l}+ \\
+ \\
+ \\
+ \\
+ \\
+\end{array}$ & $\begin{array}{l}+ \\
+ \\
+ \\
+ \\
+\end{array}$ & $\begin{array}{l}\operatorname{tr} \\
\operatorname{tr} \\
\operatorname{tr} \\
\operatorname{tr} \\
\operatorname{tr} \\
\operatorname{tr}\end{array}$ & $\begin{array}{l}\text { Negative, } \\
\text { Strongly positive, } \\
\text { Strongly positive, } \\
\text { Strongly positive, } \\
\text { Weakly positive, } \\
\text { Weakly positive, }\end{array}$ & $\begin{array}{l}-1 \\
6+ \\
8+ \\
6+ \\
1+. \\
1+.\end{array}$ \\
\hline 67 & $\begin{array}{l}\text { A. E. H. H. } \\
\text { A. E. S. F. L. } \\
\text { A. E. D. H. } \\
\text { A. I. D. H. } \\
\text { A. E. S. H. } \\
\text { A. I. S. H. }\end{array}$ & $\begin{array}{l}1: 30 \\
1: 40 \\
1: 30 \\
1: 30 \\
1: 30 \\
1: 30\end{array}$ & $\begin{array}{l}1 \mathrm{~g} \\
1 \mathrm{~g} \\
1 \mathrm{~g} \\
1 \mathrm{~g} \\
1 \mathrm{~g} \\
1 \mathrm{~g}\end{array}$ & $\begin{array}{l}+ \\
+ \\
+ \\
+ \\
+\end{array}$ & $\begin{array}{l}+ \\
+ \\
t+ \\
0 \\
+ \\
+\end{array}$ & $\begin{array}{l}0 \\
0 \\
0 \\
0 \\
0 \\
0\end{array}$ & $\begin{array}{l}+ \\
+ \\
+ \\
+ \\
+ \\
+\end{array}$ & $\begin{array}{l}+ \\
+ \\
+ \\
+ \\
+ \\
+\end{array}$ & $\begin{array}{l}0 \\
0 \\
0 \\
0 \\
0 \\
0\end{array}$ & $\begin{array}{l}\text { Negative, } \\
\text { Negative, } \\
\text { Moderately positive, } \\
\text { Strongly positive, } \\
\text { Negative, } \\
\text { Negative, }\end{array}$ & $\begin{array}{l}7 \\
2+ \\
3+\end{array}$ \\
\hline
\end{tabular}


TABLE 3-Continued

Six Drfferent Antigens Compared

\begin{tabular}{|c|c|c|c|c|c|c|c|c|c|c|c|}
\hline \multirow{3}{*}{$\begin{array}{c}\text { Number } \\
\text { of } \\
\text { Serum }\end{array}$} & \multirow{3}{*}{$\begin{array}{c}\text { Kind } \\
\text { of } \\
\text { Antigen }\end{array}$} & \multirow{3}{*}{$\begin{array}{l}\text { Antigen } \\
\text { Dilution }\end{array}$} & \multirow{3}{*}{$\begin{array}{c}\text { Ambo- } \\
\text { ceptor } \\
\text { per } \\
\text { Tube } \\
\text { Unit }\end{array}$} & \multicolumn{6}{|c|}{ Readings } & \multirow{3}{*}{\multicolumn{2}{|c|}{ Results }} \\
\hline & & & & \multicolumn{3}{|c|}{$\begin{array}{c}\text { Antigen } \\
\text { Tubes }\end{array}$} & \multicolumn{3}{|c|}{$\begin{array}{c}\text { Control } \\
\text { Tubes }\end{array}$} & & \\
\hline & & & & 1 & 2 & 3 & $1^{\prime}$ & $2^{\prime}$ & $\mathbf{3}^{\prime}$ & & \\
\hline 68 & $\begin{array}{l}\text { A. E. H. H. } \\
\text { A. E. S. F. L. } \\
\text { A. E. D. H. } \\
\text { A. I. D. H. } \\
\text { A. E. S. H. } \\
\text { A. I. S. H. }\end{array}$ & $\begin{array}{l}1: 30 \\
1: 40 \\
1: 30 \\
1: 30 \\
1: 30 \\
1: 30\end{array}$ & $\begin{array}{l}1 \mathbf{g} \\
1 \mathbf{g} \\
1 \mathbf{g} \\
1 \mathbf{g} \\
1 \mathbf{g} \\
1 \mathbf{g}\end{array}$ & $\begin{array}{l}+ \\
+ \\
+ \\
+ \\
+ \\
+\end{array}$ & $\begin{array}{l}+ \\
+ \\
\text { tr } \\
0 \\
+ \\
+\end{array}$ & $\begin{array}{l} \pm \\
\operatorname{tr} \\
0 \\
0 \\
\pm \\
\pm\end{array}$ & $\begin{array}{l}+ \\
+ \\
+ \\
+ \\
+ \\
+\end{array}$ & $\begin{array}{l}+ \\
+ \\
+ \\
+ \\
+ \\
+\end{array}$ & $\begin{array}{l} \pm \\
\pm \\
\pm \\
\pm \\
\pm\end{array}$ & $\begin{array}{l}\text { Negative, } \\
\text { Weakly positive, } \\
\text { Strongly positive, } \\
\text { Strongly positive, } \\
\text { Negative, } \\
\text { Negative, }\end{array}$ & $\begin{array}{l}1+ \\
4+ \\
5+ \\
-\end{array}$ \\
\hline 69 & $\begin{array}{l}\text { A. E. H. H. } \\
\text { A. E. S. F. L. } \\
\text { A. E. D. H. } \\
\text { A. I. D. H. } \\
\text { A. E. S. H. } \\
\text { A. I. S. H. }\end{array}$ & $\begin{array}{l}1: 30 \\
1: 40 \\
1: 30 \\
1: 30 \\
1: 30 \\
1: 30\end{array}$ & $\begin{array}{l}1 \mathbf{g} \\
1 \\
1 \\
1 \\
1 \\
1 \\
1 \\
1 \\
1 \\
\mathbf{g} \\
\mathbf{g}\end{array}$ & $\begin{array}{l}+ \\
0 \\
0 \\
+ \\
+ \\
+ \\
+\end{array}$ & $\begin{array}{l}+ \\
0 \\
0 \\
0 \\
+ \\
+\end{array}$ & $\begin{array}{l} \pm \\
0 \\
0 \\
0 \\
\pm \\
\pm\end{array}$ & $\begin{array}{l}+ \\
+ \\
+ \\
+ \\
+ \\
+\end{array}$ & $\begin{array}{l}+ \\
+ \\
+ \\
+ \\
+ \\
+\end{array}$ & $\begin{array}{l} \pm \\
\pm \\
\pm \\
\pm \\
\pm \\
\pm\end{array}$ & $\begin{array}{l}\text { Negative, } \\
\text { Strongly positive, } 1 \\
\text { Strongly positive, } \\
\text { Strongly positive, } \\
\text { Negative, } \\
\text { Negative, }\end{array}$ & $\begin{array}{l}\overrightarrow{10+} \\
10+. \\
6+. \\
-\end{array}$ \\
\hline 70 & $\begin{array}{l}\text { A. E. H. H. } \\
\text { A. E. S. F. L. } \\
\text { A. E. D. H. } \\
\text { A. I. D. H. } \\
\text { A. E. S. H. } \\
\text { A. I. S. H. }\end{array}$ & $\begin{array}{l}1: 30 \\
1: 40 \\
1: 30 \\
1: 30 \\
1: 30 \\
1: 30\end{array}$ & $\begin{array}{l}1 \mathbf{g} \\
1 \mathbf{g} \\
1 \mathbf{g} \\
1 \mathrm{~g} \\
1 \mathrm{~g} \\
1 \mathrm{~g}\end{array}$ &  & $\begin{array}{l}+ \\
0 \\
0 \\
0 \\
+ \\
+\end{array}$ & $\begin{array}{l} \pm \\
0 \\
0 \\
0 \\
\pm \\
\pm\end{array}$ & $\begin{array}{l}+ \\
+ \\
+ \\
+ \\
+ \\
+\end{array}$ & $\begin{array}{l}+ \\
+ \\
+ \\
+ \\
+\end{array}$ & $\begin{array}{l} \pm \\
\pm \\
\pm \\
\pm \\
\pm \\
\pm\end{array}$ & $\begin{array}{l}\text { Negative, } \\
\text { Strongly positive, } \\
\text { Strongly positive, } \\
\text { Strongly positive, } \\
\text { Negative, } \\
\text { Negative, }\end{array}$ & $\begin{array}{l}6+ \\
6+ \\
5-1\end{array}$ \\
\hline 71 & $\begin{array}{l}\text { A. E. H. H. } \\
\text { A. E. S. F. L. } \\
\text { A. E. D. H. } \\
\text { A. I. D. H. } \\
\text { A. E. S. H. } \\
\text { A. I. S. H. }\end{array}$ & $\begin{array}{l}1: 30 \\
1: 40 \\
1: 30 \\
1: 30 \\
1: 30 \\
1: 30\end{array}$ & $\begin{array}{ll}1 & g \\
1 & g \\
1 & g \\
1 & g \\
1 & g \\
1 & g\end{array}$ & $\begin{array}{l}+ \\
+ \\
+ \\
+ \\
+ \\
+\end{array}$ & $\begin{array}{l}+ \\
\pm \\
\pm \\
\pm \\
+ \\
+\end{array}$ & $\begin{array}{l} \pm \\
\pm 0 \\
0 \\
0 \\
\pm \\
\pm\end{array}$ & $\begin{array}{l}+ \\
+ \\
+ \\
+ \\
+ \\
+\end{array}$ & $\begin{array}{l}+ \\
+ \\
+ \\
+ \\
+ \\
+\end{array}$ & $\begin{array}{l} \pm \\
\pm \\
\pm \\
\pm \\
\pm \\
\pm\end{array}$ & $\begin{array}{l}\text { Negative, } \\
\text { Strongly positive, } \\
\text { Strongly positive, } \\
\text { Moderately positive, } \\
\text { Negative, } \\
\text { Negative, }\end{array}$ & 2 \\
\hline 72 & $\begin{array}{l}\text { A. E. H. H. } \\
\text { A. E. S. F. L. } \\
\text { A. E. D. H. } \\
\text { A. I. D. H. } \\
\text { A. E. S. H. } \\
\text { A. I. S. H. }\end{array}$ & $\begin{array}{l}1: 30 \\
1: 40 \\
1: 30 \\
1: 30 \\
1: 30 \\
1: 30\end{array}$ & $\begin{array}{ll}1 & \mathbf{g} \\
1 & \mathbf{g} \\
1 & \mathbf{g} \\
1 & \mathbf{g} \\
1 & \mathbf{g} \\
1 & \mathbf{g}\end{array}$ & $\begin{array}{l}+ \\
+ \\
+ \\
+ \\
+ \\
+\end{array}$ & $\begin{array}{l}+ \\
\pm \\
\pm \\
\mathrm{tr} \\
+ \\
+\end{array}$ & $\begin{array}{l} \pm \\
0 \\
0 \\
0 \\
\pm \\
\pm\end{array}$ & $\begin{array}{l}+ \\
+ \\
+ \\
+ \\
+ \\
+\end{array}$ & $\begin{array}{l}+ \\
+ \\
+ \\
+ \\
+ \\
+\end{array}$ & $\begin{array}{l} \pm \\
\pm \\
\pm \\
\pm \\
\pm\end{array}$ & $\begin{array}{l}\text { Negative, } \\
\text { Strongly positive, } \\
\text { Strongly positive, } \\
\text { Strongly positive, } \\
\text { Negative, } \\
\text { Negative, }\end{array}$ & $\begin{array}{l}\text {-. } \\
3+. \\
3+. \\
-\end{array}$ \\
\hline 73 & $\begin{array}{l}\text { A. E. H. H. } \\
\text { A. E. S. F. L. } \\
\text { A. E. D. H. } \\
\text { A. I. D. H. } \\
\text { A. E. S. H. } \\
\text { A. I. S. H. }\end{array}$ & $\begin{array}{l}1: 30 \\
1: 40 \\
1: 30 \\
1: 30 \\
1: 30 \\
1: 30\end{array}$ & $\begin{array}{l}1 \mathrm{~g} \\
\mathbf{1} \mathbf{g} \\
1 \mathbf{g} \\
1 \\
\mathbf{1} \\
\mathbf{1} \\
\mathbf{1} \\
\mathbf{g}\end{array}$ & $\begin{array}{l}+ \\
+ \\
+ \\
+ \\
+ \\
+\end{array}$ & $\begin{array}{l}+ \\
+ \\
+ \\
+ \\
+\end{array}$ & $\begin{array}{l} \pm \\
0 \\
0 \\
0 \\
\pm \\
\pm\end{array}$ & $\begin{array}{l}+ \\
+ \\
+ \\
+ \\
+ \\
+\end{array}$ & $\begin{array}{l}+ \\
+ \\
+ \\
+ \\
+ \\
+\end{array}$ & $\begin{array}{l} \pm \\
\frac{ \pm}{ \pm} \\
\frac{ \pm}{ \pm} \\
\frac{1}{ \pm}\end{array}$ & $\begin{array}{l}\text { Negative, } \\
\text { Moderately positive, } \\
\text { Moderately positive, } \\
\text { Moderately positive, } \\
\text { Negative, } \\
\text { Negative, }\end{array}$ & 二. \\
\hline 74 & $\begin{array}{l}\text { A. E. H. H. } \\
\text { A. E. S. F. L. } \\
\text { A. E. D. H. } \\
\text { A. I. D. H. } \\
\text { A. E. S. H. } \\
\text { A. I. S. H. }\end{array}$ & $\begin{array}{l}1: 30 \\
1: 40 \\
1: 30 \\
1: 30 \\
1: 30 \\
1: 30\end{array}$ & $\begin{array}{l}1 \mathrm{~g} \\
1 \mathrm{~g} \\
1 \mathrm{~g} \\
1 \mathrm{~g} \\
1 \mathrm{~g} \\
1 \mathrm{~g} \\
\mathbf{g}\end{array}$ & $\begin{array}{l}+ \\
+ \\
+ \\
+ \\
+\end{array}$ & $\begin{array}{l}+ \\
+ \\
+ \\
+ \\
+ \\
+\end{array}$ & $\begin{array}{l} \pm \\
\pm \\
\pm \\
0 \\
\pm \\
\pm\end{array}$ & $\begin{array}{l}+ \\
+ \\
+ \\
+ \\
+ \\
+\end{array}$ & $\begin{array}{l}+ \\
+ \\
+ \\
+ \\
+ \\
+\end{array}$ & $\begin{array}{l}\frac{ \pm}{ \pm} \\
\pm \\
\frac{ \pm}{ \pm}\end{array}$ & $\begin{array}{l}\text { Negative, } \\
\text { Negative, } \\
\text { Negative, } \\
\text { Moderately positive, } \\
\text { Negative, } \\
\text { Negative, }\end{array}$ & $2+$ \\
\hline 75 & $\begin{array}{l}\text { A. E. H. H. } \\
\text { A. E. S. F. L. } \\
\text { A. E. D. H. } \\
\text { A. I. D. H. } \\
\text { A. E. S. H. } \\
\text { A. I. S. H. }\end{array}$ & $\begin{array}{l}1: 30 \\
1: 40 \\
1: 30 \\
1: 30 \\
1: 30 \\
1: 30\end{array}$ & $\begin{array}{ll}1 & \mathbf{g} \\
1 & \mathbf{g} \\
1 & \mathbf{g} \\
1 & \mathbf{g} \\
1 & \mathbf{g} \\
1 & \mathbf{g}\end{array}$ & $\begin{array}{l}+ \\
+ \\
+ \\
\pm \\
+ \\
+\end{array}$ & $\begin{array}{l}+ \\
+ \\
0 \\
0 \\
+ \\
+\end{array}$ & $\begin{array}{l} \pm \\
0 \\
0 \\
0 \\
\pm \\
\pm\end{array}$ & $\begin{array}{l}+ \\
+ \\
+ \\
+ \\
+ \\
+\end{array}$ & $\begin{array}{l}+ \\
+ \\
+ \\
+ \\
+ \\
+\end{array}$ & $\begin{array}{l} \pm \\
\pm \\
\pm \\
\pm \\
\pm \\
\pm\end{array}$ & $\begin{array}{l}\text { Negative, } \\
\text { Strongly positive, } \\
\text { Strongly positive, } \\
\text { Strongly positive, } \\
\text { Negative, } \\
\text { Negative, }\end{array}$ & $\begin{array}{r}5+ \\
6+ \\
\end{array}$ \\
\hline 76 & $\begin{array}{l}\text { A. E. H. H. } \\
\text { A. E. S. F. L. } \\
\text { A. E. D. H. } \\
\text { A. I. D. H. } \\
\text { A. E. S. H. } \\
\text { A. I. S. H. }\end{array}$ & $\begin{array}{l}1: 30 \\
1: 40 \\
1: 30 \\
1: 30 \\
1: 30 \\
1: 30\end{array}$ & $\begin{array}{l}1 \mathrm{~g} \\
1 \mathrm{~g} \\
1 \mathrm{~g} \\
1 \mathrm{~g} \\
1 \mathrm{~g} \\
1 \mathrm{~g}\end{array}$ & $\begin{array}{l}+ \\
\pm \\
\operatorname{tr} \\
\operatorname{tr} \\
+ \\
+\end{array}$ & $\begin{array}{l}+ \\
0 \\
0 \\
0 \\
+ \\
+\end{array}$ & $\begin{array}{l} \pm \\
0 \\
0 \\
0 \\
\operatorname{tr} \\
\operatorname{tr}\end{array}$ & $\begin{array}{l}+ \\
+ \\
+ \\
+ \\
+ \\
+\end{array}$ & $\begin{array}{l}+ \\
+ \\
+ \\
+ \\
+ \\
+\end{array}$ & $\begin{array}{l} \pm \\
\pm \\
\pm \\
\pm \\
\pm \\
\pm\end{array}$ & $\begin{array}{l}\text { Negative, } \\
\text { Strongly positive, } \\
\text { Strongly positive, } \\
\text { Strongly positive, } \\
\text { Weakly positive, } \\
\text { Weakly positive, }\end{array}$ & $\therefore$ \\
\hline
\end{tabular}


TABLE 3-Continued

Six Different Antrgens Compared

\begin{tabular}{|c|c|c|c|c|c|c|c|c|c|c|c|}
\hline \multirow{3}{*}{$\begin{array}{c}\text { Number } \\
\text { of } \\
\text { Serum }\end{array}$} & \multirow{3}{*}{$\begin{array}{c}\text { Kind } \\
\text { of } \\
\text { Antigen }\end{array}$} & \multirow{3}{*}{$\begin{array}{c}\text { Antigen } \\
\text { Dilution }\end{array}$} & \multirow{3}{*}{$\begin{array}{l}\text { Ambo- } \\
\text { ceptor } \\
\text { per } \\
\text { Tube } \\
\text { Unit }\end{array}$} & \multicolumn{6}{|c|}{ Readings } & \multirow{3}{*}{\multicolumn{2}{|c|}{ Results }} \\
\hline & & & & \multicolumn{3}{|c|}{$\begin{array}{c}\text { Antigen } \\
\text { Tubes }\end{array}$} & \multicolumn{3}{|c|}{$\begin{array}{c}\text { Control } \\
\text { Tubes }\end{array}$} & & \\
\hline & & & & $I$ & 2 & 3 & $\mathbf{x}^{\prime}$ & 2 & $3^{\prime}$ & & \\
\hline 77 & $\begin{array}{l}\text { A. E. H. H. } \\
\text { A.E.S. W. L. } \\
\text { A. E. D. H. } \\
\text { A. I. D. H. } \\
\text { A. E. S. H. } \\
\text { A. I. S. H. }\end{array}$ & $\begin{array}{l}1: 30 \\
1: 40 \\
1: 30 \\
1: 30 \\
1: 30 \\
1: 30\end{array}$ & $\begin{array}{l}1 \mathrm{~g} \\
1 \mathrm{~g} \\
1 \mathrm{~g} \\
1 \mathrm{~g} \\
1 \mathrm{~g} \\
1 \mathrm{~g}\end{array}$ & $\begin{array}{l}+ \\
+ \\
\pm \\
+ \\
+\end{array}$ & $\begin{array}{l} \pm \\
0 \\
0 \\
+ \\
+ \\
+\end{array}$ & $\begin{array}{c}0 \\
0 \\
0 \\
\text { tr } \\
0 \\
\pm\end{array}$ & $\begin{array}{l}+ \\
+ \\
+ \\
+ \\
+ \\
+\end{array}$ & $\begin{array}{l}+ \\
+ \\
+ \\
+ \\
+ \\
+\end{array}$ & $\frac{ \pm}{ \pm}$ & $\begin{array}{l}\text { Strongly positive, } \\
\text { Strongly positive, } \\
\text { Strongly positive, } \\
\text { Weakly positive, } \\
\text { Moderately positive, } \\
\text { Negative, }\end{array}$ & $\begin{array}{l}3+. \\
5+. \\
6+. \\
1+. \\
2+.\end{array}$ \\
\hline 78 & $\begin{array}{l}\text { A. E. H. H. } \\
\text { A. E. S. F. L. } \\
\text { A. E. D. H. } \\
\text { A. I. D. H. } \\
\text { A. E. S. H. } \\
\text { A. I. S. H. }\end{array}$ & $\begin{array}{l}1: 30 \\
1: 40 \\
1: 30 \\
1: 30 \\
1: 30 \\
1: 30\end{array}$ & $\begin{array}{l}1 \mathrm{~g} \\
1 \mathrm{~g} \\
1 \mathrm{~g} \\
1 \mathrm{~g} \\
1 \mathrm{~g} \\
1 \mathrm{~g}\end{array}$ & $\begin{array}{l}+ \\
\operatorname{tr} \\
0 \\
+ \\
+ \\
+\end{array}$ & $\begin{array}{c}\operatorname{tr} \\
0 \\
0 \\
+ \\
\operatorname{tr} \\
+\end{array}$ & $\begin{array}{c}0 \\
0 \\
0 \\
\text { tr } \\
0 \\
0\end{array}$ & $\begin{array}{l}+ \\
+ \\
+ \\
+ \\
+\end{array}$ & $\begin{array}{l}+ \\
+ \\
+ \\
+ \\
+ \\
+\end{array}$ & $\begin{array}{l}\frac{ \pm}{ \pm} \\
⿱ 亠 䒑 \\
\pm \\
\pm \\
\pm\end{array}$ & $\begin{array}{l}\text { Strongly positive, } \\
\text { Strongly positive, } \\
\text { Strongly positive, } \\
\text { Weakly positive, } \\
\text { Strongly positive, } \\
\text { Moderately positive, }\end{array}$ & $\begin{array}{l}4+. \\
8+. \\
10+. \\
1+. \\
4+ \\
2+.\end{array}$ \\
\hline 79 & $\begin{array}{l}\text { A. E. H. H. } \\
\text { A. E.S. } X_{2} \\
\text { A. E. D. H. } \\
\text { A. I. D. H. } \\
\text { A. E. S. H. } \\
\text { A. I. S. H. }\end{array}$ & $\begin{array}{l}1: 30 \\
1: 40 \\
1: 30 \\
1: 30 \\
1: 30 \\
1: 30\end{array}$ & $\begin{array}{l}1 \mathrm{~g} \\
1 \mathrm{~g} \\
1 \mathrm{~g} \\
1 \mathrm{~g} \\
1 \mathrm{~g} \\
1 \mathrm{~g}\end{array}$ & $\begin{array}{l}\operatorname{tr} \\
0 \\
0 \\
+ \\
\text { tr } \\
+\end{array}$ & $\begin{array}{c}0 \\
0 \\
0 \\
\operatorname{tr} \\
0 \\
\pm \\
\end{array}$ & $\begin{array}{l}0 \\
0 \\
0 \\
0 \\
0 \\
0\end{array}$ & $\begin{array}{l}+ \\
+ \\
+ \\
+ \\
+\end{array}$ & $\begin{array}{l}+ \\
+ \\
+ \\
+ \\
+ \\
+ \\
+\end{array}$ & $\begin{array}{l}\operatorname{tr} \\
\operatorname{tr} \\
\operatorname{tr} \\
\operatorname{tr} \\
\operatorname{tr} \\
\mathrm{tr}\end{array}$ & $\begin{array}{l}\text { Strongly positive, } \\
\text { Strongly positive, } \\
\text { Strongly positive, } \\
\text { Strongly positive, } \\
\text { Strongly positive, } \\
\text { Moderately positlve, }\end{array}$ & $\begin{array}{l}6+. \\
8+. \\
8+. \\
3+. \\
6+. \\
2+.\end{array}$ \\
\hline 80 & $\begin{array}{l}\text { A. E. H. H. } \\
\text { A. E.S. S. I. } \\
\text { A. E. D. H. } \\
\text { A. I. D. H. } \\
\text { A. E.S.H. } \\
\text { A. L. S. H. }\end{array}$ & $\begin{array}{l}1: 30 \\
1: 40 \\
1: 30 \\
1: 30 \\
1: 30 \\
1: 30\end{array}$ & $\begin{array}{l}1 \mathrm{~g} \\
1 \mathrm{~g} \\
1 \mathrm{~g} \\
1 \mathrm{~g} \\
1 \mathrm{~g} \\
1 \mathrm{~g}\end{array}$ & $\begin{array}{l}+ \\
+ \\
+ \\
+\end{array}$ & $\begin{array}{l}+ \\
\pm \\
+\frac{ \pm}{ \pm} \\
t r \\
+ \\
+\end{array}$ & $\begin{array}{l}0 \\
0 \\
0 \\
0 \\
0 \\
0\end{array}$ & $\begin{array}{l}+ \\
+ \\
+ \\
+ \\
+ \\
+\end{array}$ & $\begin{array}{l}+ \\
+ \\
+ \\
+ \\
+\end{array}$ & $\begin{array}{l} \pm \\
\pm \\
\pm \\
\pm \\
\pm \\
\pm\end{array}$ & $\begin{array}{l}\text { Moderately positive, } \\
\text { Strongly positive, } \\
\text { Strongly positive, } \\
\text { Strongly positive, } \\
\text { Moderately positive, } \\
\text { Moderately positive, }\end{array}$ & $\begin{array}{l}2+. \\
3+. \\
3+. \\
4+. \\
2+. \\
2+.\end{array}$ \\
\hline 81 & $\begin{array}{l}\text { A. E. H. H. } \\
\text { A. E. S. F. Is } \\
\text { A. E. D. H. } \\
\text { A. I. D. H. } \\
\text { A. E. S. H. } \\
\text { A. I. S. H. }\end{array}$ & $\begin{array}{l}1: 30 \\
1: 40 \\
1: 30 \\
1: 30 \\
1: 30 \\
1: 30\end{array}$ & $\begin{array}{l}1 \mathrm{~g} \\
1 \mathrm{~g} \\
1 \mathrm{~g} \\
1 \mathrm{~g} \\
1 \mathrm{~g} \\
1 \mathrm{~g}\end{array}$ & $\begin{array}{l}+ \\
+ \\
+\end{array}$ & $\begin{array}{l}+ \\
\text { tr } \\
0 \\
+ \\
+ \\
+\end{array}$ & $\begin{array}{l}\text { tr } \\
0 \\
0 \\
\pm \\
0 \\
\pm\end{array}$ & $\begin{array}{l}+ \\
+ \\
+ \\
+ \\
+\end{array}$ & $\begin{array}{l}+ \\
+ \\
+ \\
+ \\
+\end{array}$ & $\begin{array}{l}\frac{ \pm}{ \pm} \\
\frac{ \pm}{ \pm} \\
\pm \\
\pm\end{array}$ & $\begin{array}{l}\text { Weakly positive, } \\
\text { Strongly positive, } \\
\text { Strongly positive, } \\
\text { Negative, } \\
\text { Moderately positive, } \\
\text { Negative, }\end{array}$ & $\begin{array}{l}1+. \\
4+. \\
5+. \\
2+.\end{array}$ \\
\hline 82 & $\begin{array}{l}\text { A. E. H. H. } \\
\text { A.E. S. F. L. } \\
\text { A. E. D. H. } \\
\text { A.T. D. H. } \\
\text { A.E. S. H. } \\
\text { A.I.S. H. }\end{array}$ & $\begin{array}{l}1: 30 \\
1: 40 \\
1: 30 \\
1: 30 \\
1: 30 \\
1: 30\end{array}$ & $\begin{array}{l}1 \mathrm{~g} \\
1 \mathrm{~g} \\
1 \mathrm{~g} \\
1 \mathrm{~g} \\
1 \mathrm{~g} \\
1 \mathrm{~g}\end{array}$ & $\begin{array}{l}+ \\
+ \\
+ \\
+\end{array}$ & $\begin{array}{l}+ \\
+ \\
\pm \\
+ \\
+ \\
+\end{array}$ & $\begin{array}{l}\operatorname{tr} \\
0 \\
0 \\
\pm \\
\pm \\
\pm \mathbf{t r} \\
\pm\end{array}$ & $\begin{array}{l}+ \\
+ \\
+ \\
+\end{array}$ & $\begin{array}{l}+ \\
+ \\
+ \\
+ \\
+\end{array}$ & $\begin{array}{l} \pm \\
\pm \\
\pm \\
\pm \\
\pm \\
\pm\end{array}$ & $\begin{array}{l}\text { Weakly positive, } \\
\text { Moderately positive, } \\
\text { Strongly positive, } \\
\text { Negative, } \\
\text { Weakly positive, } \\
\text { Negative, }\end{array}$ & $\begin{array}{l}1+. \\
2+. \\
3+.\end{array}$ \\
\hline 83 & $\begin{array}{l}\text { A. E. H. H. } \\
\text { A.E. S. F. L. } \\
\text { A.E.D.H. } \\
\text { A.I. H. H. } \\
\text { A.E. S. H. } \\
\text { A.I. S. H. }\end{array}$ & $\begin{array}{l}1: 30 \\
1: 40 \\
1: 30 \\
1: 30 \\
1: 30 \\
1: 30\end{array}$ & $\begin{array}{l}1 \mathrm{~g} \\
1 \mathrm{~g} \\
1 \mathrm{~g} \\
1 \mathrm{~g} \\
1 \mathrm{~g} \\
1 \mathrm{~g}\end{array}$ & $\begin{array}{l}+ \\
+ \\
+ \\
+\end{array}$ & $\begin{array}{l} \pm \\
0 \\
0 \\
+ \\
\pm \\
+\end{array}$ & $\begin{array}{c}0 \\
0 \\
0 \\
\operatorname{tr} \\
0 \\
\operatorname{tr}\end{array}$ & $\begin{array}{l}+ \\
+ \\
+ \\
+\end{array}$ & $\begin{array}{l}+ \\
+ \\
+ \\
+ \\
+\end{array}$ & $\frac{ \pm}{ \pm}$ & $\begin{array}{l}\text { Strongly positive, } \\
\text { Strongly positive, } \\
\text { Strongly positive, } \\
\text { Weakly positive, } \\
\text { Strongly positive, } \\
\text { Weakly positive, }\end{array}$ & $\begin{array}{l}3+. \\
5+. \\
5+. \\
1+. \\
3+. \\
1+.\end{array}$ \\
\hline 84 & $\begin{array}{l}\text { A. E. H.H. } \\
\text { A. E. S. F. L. } \\
\text { A. E. D. H. } \\
\text { A. I. D. H. } \\
\text { A. E. S. H. } \\
\text { A. I. S. H. }\end{array}$ & $\begin{array}{l}1: 30 \\
1: 40 \\
1: 30 \\
1: 30 \\
1: 30 \\
1: 30\end{array}$ & $\begin{array}{l}1 \mathrm{~g} \\
1 \mathrm{~g} \\
1 \mathrm{~g} \\
1 \mathrm{~g} \\
1 \mathrm{~g} \\
1 \mathrm{~g}\end{array}$ & $\begin{array}{l}+ \\
+ \\
+ \\
+\end{array}$ & $\begin{array}{l}+ \\
\text { tr } \\
\pm \\
+ \\
+ \\
+ \\
+\end{array}$ & $\begin{array}{c}\operatorname{tr} \\
0 \\
0 \\
\pm \\
0 \\
\pm\end{array}$ & $\begin{array}{l}+ \\
+ \\
+ \\
+\end{array}$ & $\begin{array}{l}\frac{1}{+} \\
+ \\
+ \\
+ \\
+\end{array}$ & 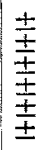 & $\begin{array}{l}\text { Weakly positive, } \\
\text { Strongly positive, } \\
\text { Strongly positive, } \\
\text { Negative, } \\
\text { Moderately positive, } \\
\text { Negative, }\end{array}$ & $\begin{array}{l}1+. \\
4+. \\
3+. \\
2+.\end{array}$ \\
\hline 85 & $\begin{array}{l}\text { A. E. H. H. } \\
\text { A. E. S. F. L. } \\
\text { A. E. D. H. } \\
\text { A. I. D. H. } \\
\text { A. E. S. H. } \\
\text { A. I. S. H. }\end{array}$ & $\begin{array}{l}1: 30 \\
1: 40 \\
1: 30 \\
1: 30 \\
1: 30 \\
1: 30\end{array}$ & $\begin{array}{l}1 \mathrm{~g} \\
1 \mathrm{~g} \\
1 \mathrm{~g} \\
1 \mathrm{~g} \\
1 \mathrm{~g} \\
1 \mathrm{~g}\end{array}$ & $\begin{array}{l}t \\
+ \\
+ \\
+ \\
+\end{array}$ & $\begin{array}{l}t \\
\pm \\
\pm \\
+ \\
+ \\
+\end{array}$ & $\begin{array}{l}\mathrm{tr} \\
0 \\
0 \\
\pm \\
\mathrm{tr} \\
\pm\end{array}$ & $\begin{array}{l}+ \\
+ \\
+ \\
+ \\
+\end{array}$ & $\begin{array}{l}+ \\
+ \\
+ \\
+ \\
+\end{array}$ & 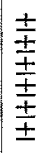 & $\begin{array}{l}\text { Weakly positive, } \\
\text { Strongly positive, } \\
\text { Strongly positive, } \\
\text { Negative, } \\
\text { Weakly positive, } \\
\text { Negative, }\end{array}$ & $\begin{array}{l}1+. \\
3+. \\
3+. \\
1+\end{array}$ \\
\hline
\end{tabular}


TABLE 3-Continued

Six Different Antigens Compared

\begin{tabular}{|c|c|c|c|c|c|c|c|c|c|c|}
\hline \multirow{3}{*}{$\begin{array}{c}\text { Number } \\
\text { of } \\
\text { Serum }\end{array}$} & \multirow{3}{*}{$\begin{array}{c}\text { Kind } \\
\text { of } \\
\text { Antigen }\end{array}$} & & \multirow{3}{*}{$\begin{array}{l}\text { Antigen } \\
\text { Dilution }\end{array}$} & & \multirow{3}{*}{$\begin{array}{l}\text { Ambo- } \\
\text { ceptor } \\
\text { pez } \\
\text { Tube } \\
\text { Onit }\end{array}$} & \multicolumn{3}{|c|}{ Readings } & \multirow{3}{*}{\multicolumn{2}{|c|}{ Results }} \\
\hline & & & & & & $\begin{array}{c}\text { Antigen } \\
\text { 'Iubes }\end{array}$ & \multicolumn{2}{|c|}{$\begin{array}{l}\text { Control } \\
\text { Tubes }\end{array}$} & & \\
\hline & & & & & & $1|2| 3$ & $1^{\prime} ! 2^{\prime}$ & $3^{\prime}$ & & \\
\hline 86 & $\begin{array}{l}\text { A. E.H.H. H. } \\
\text { A. E. S. F. L. } \\
\text { A. E. D. H. } \\
\text { A.I.D. H. } \\
\text { A. E.S.H. } \\
\text { A.I.S.H. }\end{array}$ & | & $\begin{array}{l}1: 30 \\
1: 40 \\
1: 30 \\
1: 30 \\
1: 30 \\
1: 30\end{array}$ & ! & $\begin{array}{l}1 \mathrm{~g} \\
1 \mathrm{~g} \\
1 \mathrm{~g} \\
1 \mathrm{~g} \\
1 \mathrm{~g} \\
1 \mathrm{~g} \\
1 \mathrm{~g}\end{array}$ & 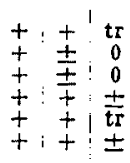 & $\begin{array}{l}+1 \\
+\quad+ \\
+t+ \\
+\quad+ \\
+1 \\
+t\end{array}$ & $\frac{ \pm \pm}{ \pm}$ & $\begin{array}{l}\text { Weakly positive, } \\
\text { Strongiy positive, } \\
\text { Strongly positive, } \\
\text { Negative, } \\
\text { Weakly positive, } \\
\text { Negatlve, }\end{array}$ & \\
\hline 87 & $\begin{array}{l}\text { A. E. H.H. } \\
\text { A. E. S. F. L. } \\
\text { A. E. D. H. } \\
\text { A. I. D. H. } \\
\text { A. F. H. H. } \\
\text { A. I. S. H. }\end{array}$ & & $\begin{array}{l}1: 30 \\
1: 40 \\
1: 30 \\
1: 00 \\
1: 30 \\
1: 30\end{array}$ & $!$ & 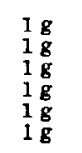 & $\begin{array}{ll:l}+ & + & 0 \\
+ & \pm & 0 \\
+ & 0 & 0 \\
+ & + & \text { tr } \\
+ & \pm & 0 \\
+ & + & \pm\end{array}$ & $\begin{array}{l}+i+ \\
+i+ \\
+i+ \\
+i+ \\
++\end{array}$ & $\frac{ \pm}{\frac{ \pm}{ \pm}}$ & $\begin{array}{l}\text { Moderately positive, } \\
\text { Strongly positive, } \\
\text { Strongly positive, } \\
\text { Weakly positive, } \\
\text { Strongly positive, } \\
\text { Negative, }\end{array}$ & \\
\hline 88 & $\begin{array}{l}\text { A. E.H.H. } \\
\text { A. E.S.F.L. } \\
\text { A.E.D.H. } \\
\text { A.I.D.H. } \\
\text { A. E.S.H. } \\
\text { A.I.S.H. }\end{array}$ & & $\begin{array}{l}1: 30 \\
1: 40 \\
1: 00 \\
1: 30 \\
1: 30 \\
1: 30\end{array}$ & $!$ & $\begin{array}{l}1 \mathrm{~g} \\
1 \mathrm{~g} \\
1 \mathrm{~g} \\
1 \mathrm{~g} \\
1 \mathrm{~g} \\
1 \mathrm{~g}\end{array}$ & 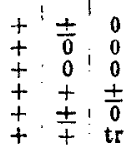 & 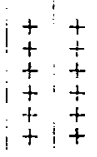 & $\frac{ \pm}{ \pm}$ & $\begin{array}{l}\text { Strongly positive, } \\
\text { Strongly positive, } \\
\text { Strongly positive, } \\
\text { Negatlive, } \\
\text { Strongly positive, } \\
\text { Weakly positive, }\end{array}$ & \\
\hline 8 & $\begin{array}{l}\text { A. E. H. H. } \\
\text { A. E.S. F. L. } \\
\text { A. D. D. H. } \\
\text { A.I. D. H. } \\
\text { A. E.S. H. } \\
\text { A.I.S. H. }\end{array}$ & ! & $\begin{array}{l}1: 30 \\
1: 40 \\
1: 00 \\
1: 30 \\
1: 30 \\
1: 30\end{array}$ & $!$ & $\begin{array}{l}1 \mathbf{g} \\
\mathbf{1} \mathbf{g} \\
1 \mathbf{g} \\
1 \mathbf{g} \\
1 \mathbf{g} \\
1 \mathbf{g} \\
\mathbf{1}\end{array}$ & $\begin{array}{lll}+ & 0 & 0 \\
\pm & 0 & 0 \\
\pm & 0 & 0 \\
+ & + & 0 \\
+ & 0 & 0 \\
+ & + & \text { tr }\end{array}$ & $\begin{array}{l}+1+ \\
+i+ \\
++ \\
+i+ \\
+1+\end{array}$ & $\begin{array}{l} \pm \\
\pm \\
\frac{ \pm}{ \pm} \\
\pm\end{array}$ & $\begin{array}{l}\text { Strongly posi } \\
\text { Strongly posi } \\
\text { strongly posi } \\
\text { Moderately po } \\
\text { Strongly posi } \\
\text { Weakly positi }\end{array}$ & \\
\hline 80 & $\begin{array}{l}\text { A. E. H. H. } \\
\text { A. E.S. W. L. } \\
\text { A. D. H. } \\
\text { A.I. D. H. } \\
\text { A. J. H. H. } \\
\text { A. I. S. H. }\end{array}$ & $\mid$ & $\begin{array}{l}1: 30 \\
1: 40 \\
1: 30 \\
1: 30 \\
1: 30 \\
1: 30\end{array}$ & 1 & $\begin{array}{l}1 \mathbf{g} \\
1 \mathbf{g} \\
\mathbf{1} \mathbf{g} \\
1 \mathbf{g} \\
1 \mathbf{g} \\
1 \mathbf{g}\end{array}$ & $\begin{array}{lll} \pm & 0 & 0 \\
\pm & 0 & 0 \\
\pm & 0 & 0 \\
\pm & + & t r \\
\pm & 0 & 0 \\
+ & + & \pm\end{array}$ & $\begin{array}{l}+ \\
+ \\
+1+ \\
+1+ \\
+ \\
+i \\
+ \\
+\end{array}$ & $\frac{ \pm}{ \pm}$ & $\begin{array}{l}\text { Strongly positlve, } \\
\text { Strongly positive, } \\
\text { Strongly positive, } \\
\text { Weakly positive, } \\
\text { Strongly positlve, } \\
\text { Negatlve, }\end{array}$ & \\
\hline 81 & $\begin{array}{l}\text { A. E. H. H. } \\
\text { A. . S. F. L. } \\
\text { A. F. D. H. } \\
\text { A. I. D. H. } \\
\text { A. E. S. } \\
\text { A.I. S. H. }\end{array}$ & | & $\begin{array}{l}1: 30 \\
1: 40 \\
1: 30 \\
1: 30 \\
1: 30 \\
1: 30\end{array}$ & i & $\begin{array}{ll}1 & \mathbf{g} \\
\mathbf{1} & \mathbf{g} \\
\mathbf{1} & \mathbf{g} \\
1 & \mathbf{g} \\
1 & \mathbf{g} \\
1 & \mathbf{g}\end{array}$ & 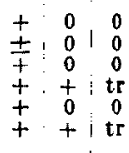 & $\begin{array}{l}+1+ \\
+1+ \\
+1+ \\
+1+ \\
+1+ \\
+1\end{array}$ & $\mid \begin{array}{l} \pm \pm \\
\pm \\
\pm \\
\pm \\
\pm\end{array}$ & $\begin{array}{l}\text { Strongly positive, } \\
\text { Strongly positive, } \\
\text { Strongly positive, } \\
\text { Weakly positive, } \\
\text { Strongly positive, } \\
\text { Weakly positive, }\end{array}$ & \\
\hline 82 & $\begin{array}{l}\text { A. E. H. H. } \\
\text { A. E.S. F. L. } \\
\text { A.E.D. H. } \\
\text { A.I.D.H. } \\
\text { A. E. H. } \\
\text { A.I.S. H. }\end{array}$ & & $\begin{array}{l}1: 30 \\
1: 40 \\
1: 30 \\
1: 30 \\
1: 30 \\
1: 30\end{array}$ & 1 & $\begin{array}{l}1 \mathbf{g} \\
1 \mathbf{g} \\
1 \mathbf{g} \\
1 \mathbf{g} \\
1 \mathbf{g}\end{array}$ & $\begin{array}{l} + \pm 0 \\
+10 \\
+ \pm 0 \\
+ \pm+1 \\
+ \pm+1\end{array}$ & $\begin{array}{l}+ \\
+ \\
+ \\
+\end{array}$ & $\begin{array}{l} \pm \\
\pm \\
\pm \\
\pm \\
\pm\end{array}$ & $\begin{array}{l}\text { Moderately positive, } \\
\text { Moderately positive, } \\
\text { Strongly positive, } \\
\text { Negative, } \\
\text { Moderately positive, }\end{array}$ & \\
\hline 93 & $\begin{array}{l}\text { A. F. H. H. } \\
\text { A.E.S. F. L. } \\
\text { A. . D. H. } \\
\text { A. I. D. H. } \\
\text { A.E. S. H. } \\
\text { A. I. S. H. }\end{array}$ & i & $\begin{array}{l}1: 30 \\
1: 40 \\
1: 30 \\
1: 30 \\
1: 30 \\
1: 30\end{array}$ & ! & $\begin{array}{l}\mathbf{1} \mathbf{g} \\
\mathbf{I} \mathbf{g} \\
\mathbf{1} \mathbf{g} \\
\mathbf{l} \mathbf{g} \\
\mathbf{1} \mathbf{g} \\
\mathbf{1} \mathbf{g}\end{array}$ & 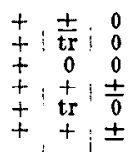 & 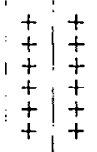 & $\begin{array}{l} \pm \\
\pm \\
\pm \\
\pm \\
\pm \\
\pm\end{array}$ & $\begin{array}{l}\text { Strongly positive, } \\
\text { Strongly positive, } \\
\text { Strongly positive, } \\
\text { Negative, } \\
\text { Strongly positive, } \\
\text { Negative, }\end{array}$ & \\
\hline 94 & $\begin{array}{l}\text { A. E. H. H. } \\
\text { A. E. S. F. L. } \\
\text { A. E. D. H. } \\
\text { A. I. D. H. } \\
\text { A. E. S. H. } \\
\text { A. I. S. H. }\end{array}$ & & $\begin{array}{l}1: 30 \\
1: 40 \\
1: 30 \\
1: 30 \\
1: 30 \\
1: 30\end{array}$ & & $\begin{array}{l}1 \mathbf{g} \\
1 \mathbf{g} \\
1 \mathbf{g} \\
1 \mathbf{g} \\
1 \mathbf{g} \\
1 \mathbf{g}\end{array}$ & $\begin{array}{ll:l}+ & 0 & 0 \\
\operatorname{tr} & 0 & 0 \\
\operatorname{tr} & 0 & 0 \\
+ & + & \mathbf{t r} \\
\operatorname{tr} & 0 & 0 \\
+ & + & \pm\end{array}$ & $\begin{array}{ll}+ & 1 \\
+ & + \\
+ & + \\
+ & + \\
+ & + \\
+ & + \\
+ & 1\end{array}$ & $\frac{ \pm}{ \pm}$ & $\begin{array}{l}\text { Strongly positjve, } \\
\text { Strongly positive, } \\
\text { Strongly positive, } \\
\text { Weakly positjve, } \\
\text { Strongly positive, } \\
\text { Negatlve, }\end{array}$ & \\
\hline
\end{tabular}


TABLE 3-Continued

Six Different Antigens Compared

\begin{tabular}{|c|c|c|c|c|c|c|c|c|c|c|c|}
\hline \multirow{3}{*}{$\begin{array}{c}\text { Number } \\
\text { of } \\
\text { Serum }\end{array}$} & \multirow{3}{*}{$\begin{array}{c}\text { Kind } \\
\text { of } \\
\text { Antigen }\end{array}$} & \multirow{3}{*}{$\begin{array}{l}\text { Antigen } \\
\text { Dilution }\end{array}$} & \multirow{3}{*}{$\begin{array}{c}\text { Ambo- } \\
\text { ceptor } \\
\text { per } \\
\text { Tube } \\
\text { Unit }\end{array}$} & \multicolumn{6}{|c|}{ Readings } & \multirow{3}{*}{\multicolumn{2}{|c|}{ Results }} \\
\hline & & & & \multicolumn{3}{|c|}{$\begin{array}{l}\text { Antigen } \\
\text { T'ubes }\end{array}$} & \multicolumn{3}{|c|}{$\begin{array}{l}\text { Control } \\
\text { Tubes }\end{array}$} & & \\
\hline & & & & 1 & 2 & 3 & $1^{\prime}$ & $2^{\prime}$ & 3 & & \\
\hline 95 & $\begin{array}{l}\text { A. E. H. H. } \\
\text { A. E. S. F. I. } \\
\text { A. E. D. H. } \\
\text { A. I. D. H. } \\
\text { A. E. S. H. } \\
\text { A. I. S. H. }\end{array}$ & $\begin{array}{l}1: 30 \\
1: 40 \\
1: 30 \\
1: 30 \\
1: 30 \\
1: 30\end{array}$ & $\begin{array}{ll}1 & \mathrm{~g} \\
1 & \mathrm{~g} \\
1 & \mathrm{~g} \\
1 & \mathrm{~g} \\
1 & \mathrm{~g} \\
1 & \mathrm{~g}\end{array}$ & $\begin{array}{l}+ \\
+ \\
+ \\
+ \\
+ \\
+\end{array}$ & $\begin{array}{l} \pm \\
0 \\
0 \\
+ \\
\operatorname{tr} \\
+\end{array}$ & $\begin{array}{c}0 \\
0 \\
0 \\
\operatorname{tr} \\
0 \\
\operatorname{tr}\end{array}$ & $\begin{array}{l}+ \\
+ \\
+ \\
+ \\
+ \\
+\end{array}$ & $\begin{array}{l}+ \\
+ \\
+ \\
+ \\
+ \\
+\end{array}$ & $\begin{array}{l}\frac{ \pm}{ \pm} \\
\pm \\
\pm \\
\pm \\
\pm\end{array}$ & $\begin{array}{l}\text { Strongly positive, } \\
\text { Strongly positive, } \\
\text { Strongly positive, } \\
\text { Weakly positive, } \\
\text { Strongly positive, } \\
\text { Weakly positive, }\end{array}$ & $\begin{array}{l}3+. \\
5+. \\
6+. \\
1+. \\
4+. \\
1+.\end{array}$ \\
\hline 96 & $\begin{array}{l}\text { A. E. H. H. } \\
\text { A. E. S. F. L. } \\
\text { A. E. D. H. } \\
\text { A. I. D. H. } \\
\text { A. E. S. H. } \\
\text { A. I. S. H. }\end{array}$ & $\begin{array}{l}1: 30 \\
1: 40 \\
1: 30 \\
1: 30 \\
1: 30 \\
1: 30\end{array}$ & $\begin{array}{ll}1 & \mathrm{~g} \\
\mathbf{1} & \mathrm{g} \\
\mathbf{1} & \mathrm{g} \\
\mathbf{1} & \mathrm{g} \\
\mathbf{1} & \mathrm{g} \\
\mathbf{1} & \mathrm{g}\end{array}$ & $\begin{array}{l}+ \\
+ \\
+ \\
+ \\
+\end{array}$ & $\begin{array}{l}+ \\
+ \\
\operatorname{tr} \\
+ \\
+ \\
+\end{array}$ & $\begin{array}{l}\operatorname{tr} \\
0 \\
0 \\
\pm \\
\operatorname{tr} \\
\pm\end{array}$ & $\begin{array}{l}+ \\
+ \\
+ \\
+ \\
+ \\
+\end{array}$ & $\begin{array}{l}+ \\
+ \\
+ \\
+ \\
+ \\
+\end{array}$ & $\begin{array}{l} \pm \\
\pm \\
\pm \\
\pm \\
\pm \\
\pm\end{array}$ & $\begin{array}{l}\text { Weakly positive, } \\
\text { Moderately positive, } \\
\text { Strongly positive, } \\
\text { Negative, } \\
\text { Weakly positive, } \\
\text { Negative, }\end{array}$ & $\begin{array}{l}1+. \\
2+. \\
4+. \\
1+.\end{array}$ \\
\hline 97 & $\begin{array}{l}\text { A. E. H. H. } \\
\text { A. E. S. F. I. } \\
\text { A. E. D. H. } \\
\text { A. I. D. H. } \\
\text { A. E. S. H. } \\
\text { A. I. S. H. }\end{array}$ & $\begin{array}{l}1: 30 \\
1: 40 \\
1: 30 \\
1: 30 \\
1: 30 \\
1: 30\end{array}$ & $\begin{array}{l}1 \mathrm{~g} \\
1 \mathrm{~g} \\
1 \mathrm{~g} \\
1 \mathrm{~g} \\
1 \mathrm{~g} \\
1 \mathrm{~g}\end{array}$ & $\begin{array}{l}+ \\
+ \\
+ \\
+ \\
+ \\
+\end{array}$ & $\begin{array}{l} \pm \\
\operatorname{tr} \\
0 \\
+ \\
\pm \\
\pm\end{array}$ & $\begin{array}{c}0 \\
0 \\
0 \\
\operatorname{tr} \\
0 \\
\pm\end{array}$ & $\begin{array}{l}+ \\
+ \\
+ \\
+ \\
+ \\
+\end{array}$ & $\begin{array}{l}+ \\
+ \\
+ \\
+ \\
+ \\
+\end{array}$ & $\begin{array}{l} \pm \\
\pm \\
\pm \\
\pm \\
\pm\end{array}$ & $\begin{array}{l}\text { Strongly positive, } \\
\text { Strongly positive, } \\
\text { Strongly positive, } \\
\text { Weakly positive, } \\
\text { Strongly positive, } \\
\text { Negative, }\end{array}$ & $\begin{array}{l}3+. \\
4+. \\
6+. \\
1+. \\
3+.\end{array}$ \\
\hline 98 & $\begin{array}{l}\text { A. E. H. H. } \\
\text { A. E. S. F. L. } \\
\text { A. E. D. H. } \\
\text { A. I. D. H. } \\
\text { A. E. S. H. } \\
\text { A. I. S. H. }\end{array}$ & $\begin{array}{l}1: 30 \\
1: 40 \\
1: 30 \\
1: 30 \\
1: 30 \\
1: 30\end{array}$ & $\begin{array}{l}1 \mathrm{~g} \\
1 \mathrm{~g} \\
1 \mathrm{~g} \\
1 \mathrm{~g} \\
1 \mathrm{~g} \\
1 \mathrm{~g}\end{array}$ & $\begin{array}{l}0 \\
0 \\
0 \\
+ \\
0 \\
+\end{array}$ & $\begin{array}{c}0 \\
0 \\
0 \\
0 \\
0 \\
\operatorname{tr}\end{array}$ & $\begin{array}{l}0 \\
0 \\
0 \\
0 \\
0 \\
0\end{array}$ & $\begin{array}{l}+ \\
+ \\
+ \\
+ \\
+ \\
+\end{array}$ & $\begin{array}{l}+ \\
+ \\
+ \\
+ \\
+ \\
+\end{array}$ & $\begin{array}{l}\operatorname{tr} \\
\operatorname{tr} \\
\operatorname{tr} \\
\operatorname{tr} \\
\operatorname{tr} \\
\operatorname{tr}\end{array}$ & $\begin{array}{l}\text { Strongly positive, } \\
\text { Strongly positive, } \\
\text { Strongly positive, } \\
\text { Strongly positive, } \\
\text { Strongly positive, } \\
\text { Strongly positive, }\end{array}$ & $\begin{array}{l}8+. \\
8+. \\
8+. \\
4+. \\
8+. \\
3+.\end{array}$ \\
\hline$\not 9$ & $\begin{array}{l}\text { A. E. H. H. } \\
\text { A. E. S. F. I. } \\
\text { A. E. D. H. } \\
\text { A. I. D. H. } \\
\text { A. E. S. H. } \\
\text { A. I. S. H. }\end{array}$ & $\begin{array}{l}1: 30 \\
1: 40 \\
1: 30 \\
1: 30 \\
1: 30 \\
1: 30\end{array}$ & $\begin{array}{l}1 \mathrm{~g} \\
1 \mathrm{~g} \\
1 \mathrm{~g} \\
\mathbf{1} \mathrm{g} \\
\mathbf{1} \mathbf{g} \\
1 \mathbf{g}\end{array}$ & $\begin{array}{l}0 \\
0 \\
0 \\
+ \\
\mathbf{t r} \\
+\end{array}$ & $\begin{array}{l}0 \\
0 \\
0 \\
\pm \\
0 \\
\pm\end{array}$ & $\begin{array}{l}0 \\
0 \\
0 \\
0 \\
0 \\
0\end{array}$ & $\begin{array}{l}+ \\
+ \\
+ \\
+ \\
+ \\
+\end{array}$ & $\begin{array}{l}+ \\
+ \\
+ \\
+ \\
+ \\
+\end{array}$ & $\begin{array}{l}\operatorname{tr} \\
\operatorname{tr} \\
\operatorname{tr} \\
\operatorname{tr} \\
\operatorname{tr} \\
\operatorname{tr}\end{array}$ & $\begin{array}{l}\text { Strongly positive, } \\
\text { Strongly positive, } \\
\text { Strongly positive, } \\
\text { Moderately positive, } \\
\text { Strongly positive, } \\
\text { Moderately positive, }\end{array}$ & $\begin{array}{l}8+. \\
8+. \\
8+. \\
2+. \\
6+. \\
2+.\end{array}$ \\
\hline 100 & $\begin{array}{l}\text { A. E. H. H. } \\
\text { A. E. S. E. L. } \\
\text { A. E. D. H. } \\
\text { A. I. D. H. } \\
\text { A. E. S. H. } \\
\text { A. I. S. H. }\end{array}$ & $\begin{array}{l}1: 30 \\
1: 40 \\
1: 30 \\
1: 30 \\
1: 30 \\
1: 30\end{array}$ & $\begin{array}{ll}1 & g \\
1 & g \\
1 & \mathbf{g} \\
1 & g \\
1 & g \\
1 & g\end{array}$ & $\begin{array}{l}0 \\
\text { tr } \\
0 \\
+ \\
+ \\
+\end{array}$ & $\begin{array}{l}0 \\
0 \\
0 \\
+ \\
0 \\
+\end{array}$ & $\begin{array}{l}0 \\
0 \\
0 \\
0 \\
0 \\
0\end{array}$ & $\begin{array}{l}+ \\
+ \\
+ \\
+ \\
+ \\
+\end{array}$ & $\begin{array}{l}+ \\
+ \\
+ \\
+ \\
+ \\
+\end{array}$ & $\begin{array}{l}\operatorname{tr} \\
\operatorname{tr} \\
\operatorname{tr} \\
\operatorname{tr} \\
\operatorname{tr} \\
\operatorname{tr}\end{array}$ & $\begin{array}{l}\text { Strongly positive, } \\
\text { Strongly positive, } \\
\text { Strongly positive, } \\
\text { Weakly positive, } \\
\text { Strongly positive, } \\
\text { Weakly positive, }\end{array}$ & $\begin{array}{l}8+. \\
6+. \\
8+. \\
1+. \\
4+. \\
1+.\end{array}$ \\
\hline
\end{tabular}

insoluble antigen of dog heart usually gave weaker positive results than the alcoholic extract of human heart, but occasionally it gave a stronger positive result than any of the others. The results obtained with alcoholic extract of sheep heart were almost identical with those obtained with alcoholic extract of human heart, while the acetone insoluble antigen of sheep heart reacted somewhat weaker.

\section{TEsT 4}

In order to determine whether glycerol in any way influenced the result of the Wassermann reaction with dog antigen, 10 serums were tested before and after having been glycerolated. Each serum was divided into 2 portions, $\mathrm{A}$ and $\mathrm{B}$, and both portions were heated to about $56 \mathrm{C}$. for 30 minutes. 
Portion A was diluted with an equal volume of salt solution, Portion B was mixed with an equal volume of glycerol, and both portions were tested against alcoholic extract of human heart and against alcoholic extract of dog heart.

TABLE 4

Nonglycerolated and Grycerolated Serum Compared

\begin{tabular}{|c|c|c|c|c|c|c|c|c|c|c|c|}
\hline \multirow{3}{*}{$\begin{array}{c}\text { Number } \\
\text { of } \\
\text { Serum }\end{array}$} & \multirow{3}{*}{$\begin{array}{c}\text { Portions } \\
\text { A=Non- } \\
\text { glycero- } \\
\text { lated } \\
\text { B=Glycer- } \\
\text { olated }\end{array}$} & \multirow{3}{*}{$\begin{array}{l}\text { Kind } \\
\text { of } \\
\text { Antigen }\end{array}$} & \multirow{3}{*}{$\begin{array}{c}\text { Ambo- } \\
\text { ceptor } \\
\text { per } \\
\text { Tube } \\
\text { Unit }\end{array}$} & \multicolumn{6}{|c|}{ Readings } & \multirow{3}{*}{\multicolumn{2}{|c|}{ Results }} \\
\hline & & & & \multicolumn{3}{|c|}{$\begin{array}{l}\text { Antigen } \\
\text { Tubes }\end{array}$} & \multicolumn{3}{|c|}{$\begin{array}{l}\text { Control } \\
\text { Tubes }\end{array}$} & & \\
\hline & & & & 1 & 21 & 3 & $x^{\prime}$ & $2^{\prime}$ & $3^{\prime}$ & & \\
\hline 101 & $\begin{array}{l}\mathrm{A} \\
\mathrm{A} \\
\mathbf{B} \\
\mathbf{B}\end{array}$ & $\begin{array}{l}\text { A. E. H. H. } \\
\text { A. E. D. H. } \\
\text { A. E. H. H. } \\
\text { A. E. D. H. }\end{array}$ & $\begin{array}{l}1 \\
1 \\
1 \mathrm{~g} \\
1 \mathrm{~g}\end{array}$ & $\begin{array}{l}+ \\
+ \\
+ \\
+\end{array}$ & $\begin{array}{l}+ \\
+ \\
+ \\
+\end{array}$ & $\begin{array}{l}\operatorname{tr} \\
\operatorname{tr} \\
\pm \\
\pm\end{array}$ & $\begin{array}{l}+ \\
+ \\
+ \\
+\end{array}$ & $\begin{array}{l}+ \\
+ \\
+ \\
+\end{array}$ & $\begin{array}{l}\operatorname{tr} \\
\operatorname{tr} \\
\pm \\
\pm\end{array}$ & $\begin{array}{l}\text { Negative, } \\
\text { Negative, } \\
\text { Negative, } \\
\text { Negative, }\end{array}$ & 二. \\
\hline 102 & $\begin{array}{l}\mathbf{A} \\
\mathbf{A} \\
\mathbf{B} \\
\mathbf{B}\end{array}$ & $\begin{array}{l}\text { A. E. H. H. } \\
\text { A. E. D. H. } \\
\text { A. E. H. H. } \\
\text { A. E. D. H. }\end{array}$ & $\begin{array}{l}1 \\
1 \\
1 \mathrm{~g} \\
1 \mathrm{~g}\end{array}$ & $\begin{array}{l}+ \\
+ \\
+ \\
+\end{array}$ & $\begin{array}{c}+ \\
+ \\
+ \\
+\end{array}$ & $\begin{array}{l} \pm \\
\pm \\
\pm \\
\pm\end{array}$ & $\begin{array}{l}+ \\
+ \\
+ \\
+\end{array}$ & $\begin{array}{l}+ \\
+ \\
+ \\
+\end{array}$ & $\begin{array}{l} \pm \\
\pm \\
\pm \\
\pm\end{array}$ & $\begin{array}{l}\text { Negative, } \\
\text { Negative, } \\
\text { Negative, } \\
\text { Negative, }\end{array}$ & $=$ \\
\hline 103 & $\begin{array}{l}\mathbf{A} \\
\mathbf{A} \\
\mathbf{B} \\
\mathbf{B}\end{array}$ & $\begin{array}{l}\text { A. E. H. H. } \\
\text { A. E. D. H. } \\
\text { A. E. H. H. } \\
\text { A. E. D. H. }\end{array}$ & $\begin{array}{l}1 \\
1 \\
1 \mathrm{~g} \\
1 \mathrm{~g}\end{array}$ & $\begin{array}{l}+ \\
+ \\
+\end{array}$ & $\begin{array}{l}+ \\
+ \\
+ \\
+\end{array}$ & $\begin{array}{l} \pm \\
\pm \\
\pm\end{array}$ & $\begin{array}{l}+ \\
+ \\
+ \\
+\end{array}$ & $\begin{array}{l}+ \\
+ \\
+ \\
+\end{array}$ & $\begin{array}{l} \pm \\
\pm \\
\pm \pm ⿱ 亠 ⿻ \\
\pm\end{array}$ & $\begin{array}{l}\text { Negative, } \\
\text { Negative, } \\
\text { Negative, } \\
\text { Negative, }\end{array}$ & $\begin{array}{l}= \\
=\end{array}$ \\
\hline 104 & $\begin{array}{l}\mathbf{A} \\
\mathbf{A} \\
\mathbf{B} \\
\mathbf{B}\end{array}$ & $\begin{array}{l}\text { A. E. H. H. } \\
\text { A. E. D. H. } \\
\text { A. E. H. H. } \\
\text { A. E. D. H. }\end{array}$ & $\begin{array}{l}1 \\
1 \\
1 \mathbf{g} \\
1 \mathbf{g}\end{array}$ & $\begin{array}{l}+ \\
+ \\
+ \\
+\end{array}$ & $\begin{array}{l}+ \\
+ \\
+ \\
+\end{array}$ & $\begin{array}{l} \pm \\
\pm \\
\pm \\
\pm\end{array}$ & $\begin{array}{l}+ \\
+ \\
+ \\
+\end{array}$ & $\begin{array}{l}+ \\
+ \\
+ \\
+\end{array}$ & $\begin{array}{l} \pm \\
\pm \\
\pm\end{array}$ & $\begin{array}{l}\text { Negative, } \\
\text { Negative, } \\
\text { Negative, } \\
\text { Negative, }\end{array}$ & $=$ \\
\hline 105 & $\begin{array}{l}\mathbf{A} \\
\mathbf{A} \\
\mathbf{B} \\
\mathbf{B}\end{array}$ & $\begin{array}{l}\text { A. E. H. H. } \\
\text { A. E. D. H. } \\
\text { A. E. H. H. } \\
\text { A. E. D. H. }\end{array}$ & $\begin{array}{l}1 \\
1 \\
1 \mathrm{~g} \\
1 \mathrm{~g}\end{array}$ & $\begin{array}{l}+ \\
+ \\
+ \\
+\end{array}$ & $\begin{array}{l}+ \\
+ \\
+ \\
+\end{array}$ & $\frac{ \pm}{ \pm}$ & $\begin{array}{l}+ \\
+ \\
+ \\
+\end{array}$ & $\begin{array}{l}+ \\
+ \\
+ \\
+ \\
+\end{array}$ & 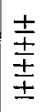 & $\begin{array}{l}\text { Negative, } \\
\text { Negative, } \\
\text { Negative, } \\
\text { Negative, }\end{array}$ & $=$ \\
\hline 106 & $\begin{array}{l}\mathbf{A} \\
\mathbf{A} \\
\mathbf{B} \\
\mathbf{B}\end{array}$ & $\begin{array}{l}\text { A. E. H. H. } \\
\text { A. E. D. }{ }^{H} \text {. } \\
\text { A. E. H. H. } \\
\text { A. E. D. } H .\end{array}$ & $\begin{array}{l}\mathbf{1} \\
\mathbf{1} \\
\mathbf{1} \mathbf{g} \\
1 \mathbf{g}\end{array}$ & $\begin{array}{l}+ \\
+ \\
+\end{array}$ & $\begin{array}{l}+ \\
+ \\
+ \\
\pm\end{array}$ & 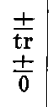 & $\begin{array}{l}+ \\
+ \\
+ \\
+\end{array}$ & $\begin{array}{l}+ \\
+ \\
+ \\
+\end{array}$ & $\frac{ \pm}{ \pm+}$ & $\begin{array}{l}\text { Negative, } \\
\text { Weakly positive, } \\
\text { Negative, } \\
\text { Strongly positive, }\end{array}$ & $\frac{1}{3+}$ \\
\hline 107 & $\begin{array}{l}\mathbf{A} \\
\mathbf{A} \\
\mathbf{B} \\
\mathbf{B}\end{array}$ & $\begin{array}{l}\text { A. E. H. H. } \\
\text { A. E. D. H. } \\
\text { A. E. H. H. } \\
\text { A. E. D. H. }\end{array}$ & $\begin{array}{l}1 \\
1 \\
1 \mathrm{~g} \\
1 \mathrm{~g}\end{array}$ & $\begin{array}{l}+ \\
+ \\
+ \\
+\end{array}$ & $\begin{array}{c}+ \\
\pm \\
+ \\
0\end{array}$ & $\begin{array}{l} \pm \\
0 \\
\pm \\
0\end{array}$ & $\begin{array}{l}+ \\
+ \\
+ \\
+\end{array}$ & $\begin{array}{l}+ \\
+ \\
+ \\
+\end{array}$ & $\frac{ \pm}{ \pm \pm}$ & $\begin{array}{l}\text { Negative, } \\
\text { Strongly positive, } \\
\text { Negative, } \\
\text { Strongly positive, }\end{array}$ & $\overrightarrow{3+}$ \\
\hline 108 & $\begin{array}{l}\mathbf{A} \\
\mathbf{A} \\
\mathbf{B} \\
\mathbf{B}\end{array}$ & $\begin{array}{l}\text { A. E. H. H. } \\
\text { A. E. D. H. } \\
\text { A. E. H. H. } \\
\text { A. E. D. H. }\end{array}$ & $\begin{array}{l}1 \\
1 \\
1 \mathrm{~g} \\
1 \mathrm{~g}\end{array}$ & $\begin{array}{l}+ \\
+ \\
+ \\
+\end{array}$ & $\begin{array}{l}+ \\
+ \\
+ \\
\pm\end{array}$ & $\begin{array}{l} \pm \\
\operatorname{tr} \\
\frac{ \pm}{0}\end{array}$ & $\begin{array}{l}+ \\
+ \\
+ \\
+\end{array}$ & $\begin{array}{l}+ \\
+ \\
+ \\
+\end{array}$ & $\begin{array}{l} \pm \\
\pm \\
\pm \\
\pm \\
\pm\end{array}$ & $\begin{array}{l}\text { Negative, } \\
\text { Weakly positive, } \\
\text { Negative, } \\
\text { Strongly positive, }\end{array}$ & $\overrightarrow{1+}$ \\
\hline 109 & $\begin{array}{l}\mathbf{A} \\
\mathbf{A} \\
\mathbf{B} \\
\mathbf{B}\end{array}$ & $\begin{array}{l}\text { A. E. H. H. } \\
\text { A. E. D. H. } \\
\text { A. E. H. H. } \\
\text { A. E. D. H. }\end{array}$ & $\begin{array}{l}1 \\
1 \\
1 \mathrm{~g} \\
1 \mathrm{~g}\end{array}$ & $\begin{array}{l}+ \\
+ \\
+ \\
+\end{array}$ & $\begin{array}{l}+ \\
+ \\
+ \\
\pm\end{array}$ & $\begin{array}{l} \pm \\
\operatorname{tr} \\
\pm \\
\end{array}$ & $\begin{array}{l}+ \\
+ \\
+ \\
+\end{array}$ & $\begin{array}{l}+ \\
+ \\
+ \\
+\end{array}$ & $\frac{ \pm}{ \pm}$ & $\begin{array}{l}\text { Negative, } \\
\text { Weakly positive, } \\
\text { Negative, } \\
\text { Strongly positive, }\end{array}$ & $\frac{-}{1+}$ \\
\hline 110 & $\begin{array}{l}\mathbf{A} \\
\mathbf{A} \\
\mathbf{B} \\
\mathbf{B}\end{array}$ & $\begin{array}{l}\text { A. E. H. H. } \\
\text { A. E. D. H. } \\
\text { A. E. H. H. } \\
\text { A. E. D. H. }\end{array}$ & $\begin{array}{l}1 \\
1 \\
1 g \\
1 g\end{array}$ & $\begin{array}{l}+ \\
+ \\
+ \\
+\end{array}$ & $\begin{array}{l}+ \\
+ \\
+ \\
\pm\end{array}$ & $\begin{array}{l} \pm \\
\pm ? \\
0\end{array}$ & $\begin{array}{l}+ \\
+ \\
+ \\
+\end{array}$ & $\begin{array}{l}+ \\
+ \\
+ \\
+ \\
+\end{array}$ & $\begin{array}{l} \pm \\
\pm \\
\pm \\
\pm\end{array}$ & $\begin{array}{l}\text { Negative, } \\
\text { Faintly positivè, } \\
\text { Negative, } \\
\text { Strongly positive, }\end{array}$ & $\underset{ \pm}{ \pm}$ \\
\hline
\end{tabular}

Table 4 shows that all serums which gave positive results with alcoholic extract of dog heart after they had been mixed with glycerol also gave positive results before they had been mixed with glycerol. 
'The glycerolated portions gave stronger positive results than did the nonglycerolated portions, but this is to be expected with any antigen. Glycerol makes the test more sensitive.

TEST 5

Eight serums were tested against alcoholic extract of dog heart before and after their natural antidog amboceptor had been absorbed. Each serum was divided into two portions, A and B. Portion A was left whole while from Portion B the antidog amboceptor was absorbed. Both portions were tested against alcoholic extract of dog heart.

TABLE 5

Human Serum Tested Before and After Absorption of Antidog Amboceptor

\begin{tabular}{|c|c|c|c|c|c|c|c|c|c|c|c|}
\hline \multirow{3}{*}{$\begin{array}{c}\text { Number } \\
\text { of } \\
\text { Seram }\end{array}$} & \multirow{3}{*}{$\begin{array}{l}\text { Portions } \\
\text { A, Ambo- } \\
\text { ceptor Not } \\
\text { Absorbed } \\
\text { B, Ambo- } \\
\text { ceptor } \\
\text { Absorbed }\end{array}$} & \multirow{3}{*}{$\begin{array}{l}\text { Kind } \\
\text { of } \\
\text { Antigen }\end{array}$} & \multirow{3}{*}{$\begin{array}{l}\text { Ambo- } \\
\text { ceptor } \\
\text { per } \\
\text { Tube } \\
\text { Unit }\end{array}$} & \multicolumn{6}{|c|}{ Readings } & \multirow{3}{*}{\multicolumn{2}{|c|}{ Results }} \\
\hline & & & & \multicolumn{3}{|c|}{$\begin{array}{l}\text { Antigen } \\
\text { Tubes }\end{array}$} & \multicolumn{3}{|c|}{$\begin{array}{l}\text { Control } \\
\text { Tubes }\end{array}$} & & \\
\hline & & & & 1 & 2 & 3 & $1^{\prime}$ & 2 & $3^{\prime}$ & & \\
\hline 111 & $\begin{array}{l}\mathbf{A} \\
\mathbf{B}\end{array}$ & $\begin{array}{l}\text { A. E. D. H. } \\
\text { A. E. D. H. }\end{array}$ & $\begin{array}{l}1 \mathrm{~g} \\
\mathbf{1} \mathrm{g}\end{array}$ & + & \pm & $\begin{array}{l}0 \\
0\end{array}$ & + & $\begin{array}{l}+ \\
+\end{array}$ & \pm & $\begin{array}{l}\text { Strongly porsitive, } \\
\text { Strongly positive, }\end{array}$ & $\begin{array}{l}3+. \\
3+\text {. }\end{array}$ \\
\hline 112 & $\underset{\mathbf{B}}{\mathbf{A}}$ & $\begin{array}{l}\text { A. E. D. H. } \\
\text { A. E. D. H. }\end{array}$ & $1 \mathrm{~g}$ & $\dot{+}$ & + & $\begin{array}{l}0 \\
0\end{array}$ & $\begin{array}{l}+ \\
+\end{array}$ & $\stackrel{+}{+}$ & \pm & $\begin{array}{l}\text { Moderately positive } \\
\text { Moderately positive }\end{array}$ & $2+$ \\
\hline 113 & $\begin{array}{l}\mathbf{A} \\
\mathbf{B}\end{array}$ & $\begin{array}{l}\text { A. E. D. H. } \\
\text { A. E. D. H. }\end{array}$ & $\begin{array}{l}1 \mathrm{~g} \\
1 \mathrm{~g}\end{array}$ & + & \pm & $\begin{array}{l}0 \\
0\end{array}$ & + & $\stackrel{+}{t}$ & $\stackrel{ \pm}{ \pm}$ & $\begin{array}{l}\text { Strongly positive, } \\
\text { Strongly positive, }\end{array}$ & $\begin{array}{l}3+. \\
3+\end{array}$ \\
\hline 114 & $\begin{array}{l}\mathbf{A} \\
\mathbf{B}\end{array}$ & $\begin{array}{l}\text { A. E. D. H. } \\
\text { A. E. D. H. }\end{array}$ & $\begin{array}{l}1 \mathrm{~g} \\
1 \mathrm{~g}\end{array}$ & $\dot{t}$ & \pm & $\begin{array}{l}0 \\
0\end{array}$ & + & $\stackrel{+}{+}$ & \pm & $\begin{array}{l}\text { Strongly positive, } \\
\text { Strongly positive, }\end{array}$ & $\begin{array}{l}3+. \\
3+\text {. }\end{array}$ \\
\hline 115 & $\begin{array}{l}\mathbf{A} \\
\mathbf{B}\end{array}$ & $\begin{array}{l}\text { A. E. D. H. } \\
\text { A. E. D. } \dot{H} \text {. }\end{array}$ & $\begin{array}{l}1 \mathrm{~g} \\
1 \mathrm{~g}\end{array}$ & + & $\begin{array}{l}0 \\
0\end{array}$ & $\begin{array}{l}0 \\
0\end{array}$ & + & $\dot{+}+$ & \pm & $\begin{array}{l}\text { Strongly positive, } \\
\text { Strongly positive, }\end{array}$ & $\begin{array}{l}5+ \\
5+\end{array}$ \\
\hline 116 & $\begin{array}{l}\text { A } \\
\text { B. }\end{array}$ & $\begin{array}{l}\text { A. E. D. H. } \\
\text { A. E. D. H. }\end{array}$ & $\begin{array}{l}1 \mathrm{~g} \\
1 \mathrm{~g}\end{array}$ & \pm & $\begin{array}{l}0 \\
0\end{array}$ & $\begin{array}{l}0 \\
0\end{array}$ & $\begin{array}{l}+ \\
+\end{array}$ & + & \pm & $\begin{array}{l}\text { Strongly positive, } \\
\text { Strongly positive, }\end{array}$ & $\begin{array}{l}6+. \\
6+.\end{array}$ \\
\hline 1.17 & $\begin{array}{l}\mathrm{A} \\
\mathrm{B}\end{array}$ & $\begin{array}{l}\text { A. E. D. H. } \\
\text { A. E. D. H. }\end{array}$ & $\begin{array}{l}1 \mathrm{~g} \\
1 \mathrm{~g}\end{array}$ & + & \pm & $\begin{array}{l}0 \\
0\end{array}$ & + & + & \pm & $\begin{array}{l}\text { Strongly positive, } \\
\text { Strongly positive, }\end{array}$ & $\begin{array}{l}3+. \\
3+.\end{array}$ \\
\hline 118 & $\underset{\mathbf{B}}{\mathbf{A}}$ & $\begin{array}{l}\text { A. E. D. H. } \\
\text { A. E. D. H. }\end{array}$ & $\begin{array}{l}1 \mathrm{~g} \\
1 \mathrm{~g}\end{array}$ & + & $\operatorname{tr}$ & $\begin{array}{l}0 \\
0\end{array}$ & $\begin{array}{l}+ \\
+\end{array}$ & $\begin{array}{l}+ \\
+\end{array}$ & \pm & $\begin{array}{l}\text { Strongly positive, } \\
\text { Strongly positive, }\end{array}$ & $\begin{array}{l}4+. \\
4+\end{array}$ \\
\hline
\end{tabular}

The results are shown in Table 5. Absorbing the natural antidog amboceptor from human serum did not affect the results obtained with the Wassermann test using alcoholic extract of dog heart as antigen.

\section{SUM MARY}

Antigen diluted with the salt solution slowly so as to give an opalescent solution gave many more positive results with the Wassermann test than did antigen which was diluted rapidly enough to give a clear solution.

Adding the antigen to the human serum before the complement gave results identical with those obtained when the complement was added before the antigen. 
Antigen supposed to be alcoholic extract of syphilitic fetal liver and antigen prepared from dog heart gave many more positive results than did alcoholic extract of human heart. As no other signs or symptoms of syphilis could be detected these were considered false positive results, and these antigens were discarded as being unreliable. Antigen prepared from sheep heart gave results almost identical with those given by antigen prepared from human heart.

The glycerol added to the human serum cannot be held responsible for the false positive results obtained.

Previous absorption of the natural antidog amboceptor from the human serums did not eliminate the false positive results. 